\title{
Comprehensive Studies on Dual Excitation Behavior of Double Proton versus Charge Transfer in 4-( $N$-Substituted amino)-1H-pyrrolo[2,3-b]pyridines
}

\author{
Chung-Chih Cheng, ${ }^{\dagger}$ Chen-Pin Chang, ${ }^{\dagger}$ Wei-Shan Yu,, Fa-Tsai Hung, ${ }^{\S}$ Yun-I Liu,, \\ Guo-Ray Wu," and Pi-Tai Chou*," \\ Department of Chemistry, Fu-Jen Catholic University, 242, Taipei, Taiwan, Republic of China, Department of \\ Chemistry, National Taiwan University, 106, Taipei, Taiwan, Republic of China, The National Hu-Wei Institute \\ of Technology, Yunlin, Taiwan, Republic of China, and Department of Chemistry and Biochemistry, National \\ Chung Cheng University, 621, Chia-Yi, Taiwan, Republic of China
}

Received: May 21, 2002; In Final Form: December 13, 2002

\begin{abstract}
Comprehensive spectroscopic and dynamical studies on the dual excitation behavior of proton vs charge transfer for 4-(dimethylamino)-1H-pyrrolo[2,3-b]pyridine (DPP) and its related derivatives are reported. In cyclohexane, DPP dimer and/or dual hydrogen-bonded complex are formed with association constants $K_{\mathrm{a}}$ as high as $\sim 4.2 \times 10^{3}$ and $5.2 \times 10^{4} \mathrm{M}^{-1}$ (e.g., the DPP/acetic acid complex) at $298 \mathrm{~K}$, respectively, which upon electronic excitation undergo ultrafast rate $\left(\gg 6.7 \times 10^{10} \mathrm{~s}^{-1}\right)$ of double-proton transfer, resulting in a unique tautomer emission. Dual fluorescence was observed in polar, aprotic solvents, in which the large Stokes shifted emission band originates from the charge-transfer species incorporating a dimethylamine and pyridine ring as electron donor and acceptor, respectively. Detailed solvent-polarity and temperature-dependent studies in combination with theoretical approaches have been performed to determine the excited-state chargetransfer properties such as dipole moment, orbital configuration, etc. Supplementary support for the dual charge/proton-transfer behavior was provided by the comparative spectroscopy and dynamics of various DPPrelated derivatives. Further time-resolved measurements conclude that dual emissions share a common FranckCondon excited state but undergo two independent relaxation channels. In protic solvents, such as ethanol, following fast solvent relaxation dynamics, the excited charge-transfer state further undergoes a solvent (i.e. alcohol) assisted proton-transfer reaction. The charge versus proton-transfer emission can be distinguished via the temporal spectral evolution. The results demonstrate DPP to be a unique model among 7-azaindole analogues in which the interplay between charge and proton-transfer reactions is operative in the excited state.
\end{abstract}

\section{Introduction}

In their seminal studies, Taylor et al. ${ }^{1}$ found that the first excited singlet state of 7-azaindole (7AI) dual hydrogen-bonded (HB) dimer undergoes an excited-state double proton transfer (ESDPT), resulting in a large Stokes-shifted tautomer emission (e.g., $\lambda_{\max } \sim 480 \mathrm{~nm}$ in cyclohexane). This dual hydrogenbonding system has ever since been recognized as a simplified model for the base pair of DNA. At the molecular level, the ESDPT process provides one possible mechanism for the mutation due to a "misprint" induced by the proton-transfer tautomerism of a specific DNA base pair during replication, recording an error message. ${ }^{2-5}$ On this basis, much research has focused on the spectroscopy and dynamics ${ }^{1-3,6-17}$ as well as theoretical approaches ${ }^{18-20}$ of ESDPT in the 7AI dimer. Conversely, via the formation of a 7AI(host)/guest HB complex, the dynamics of ESDPT incorporating various types of guest molecules has also received considerable attention through both experimental $^{21-26}$ and theoretical approaches. ${ }^{27-30}$ Studies of 7AI complexed to single molecules of carboxylic acids and lactams have revealed rapid ESDPT reaction, ${ }^{26 \mathrm{~b}-\mathrm{d}}$ especially

\footnotetext{
* To whom correspondence should be addressed.

$\dagger$ Department of Chemistry, Fu-Jen Catholic University.

$\doteqdot$ Department of Chemistry, National Taiwan University.

$\S$ The National Hu-Wei Institute of Technology.

" Department of Chemistry and Biochemistry, National Chung Cheng University.
}

for the catalytic type of reaction where the guest molecule (e.g., acetic acid) remains unchanged during the proton-transfer reaction. In bulk alcohols and water the dynamics of solvent assisted ESDPT in 7AI and its analogue 7-azatryptophan have been successfully applied to probe the solvation and/or protein dynamics. ${ }^{21-25}$ During the past few years, focus on the chemical modification of 7AI has received particular interest to study the substituent effect on the proton transfer reaction. It has been shown that the number as well as the position of the nitrogen atom in either a five- or six-member ring system of 7AI alters the relative ESDPT thermodynamics, especially in the noncatalytic type of proton-transfer reaction. ${ }^{31}$ The generalization of amine-imine type of tautomerism in 7AI and its corresponding analogues has been verified via the hydrogenation of the $\mathrm{C}_{2}-$ $\mathrm{C}_{3}$ double bond in 7AI, forming 7-azaindoline. ${ }^{32}$ The results open up a study of ESDPT extended to a DNA base such as adenine derivatives possessing similar type of tautomerism proposed in the mutation process. ${ }^{33}$ On the other hand, based on the design of 3-cyano-7-azaindole, a steady state tautomer emission in aqueous solution has been unambiguously resolved and successfully applied as a model to closely examine various proposed mechanisms of excited-state proton-transfer reactions for $7 \mathrm{AI}$ in pure water. ${ }^{34}$

In another approach, in the previous communication ${ }^{35}$ we reported the dual excitation behavior of excited-state biprotonic 

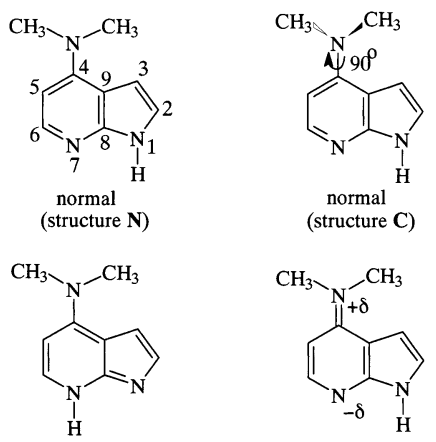

(proton-transfer tautomer) (charge-transfer tautomer)

DPP<smiles>CN(C)c1ccnc2c1ccn2C</smiles>

1MDPP

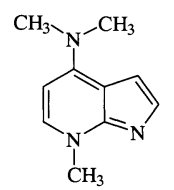

7MDPP

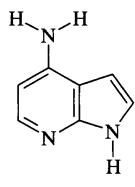

APP
Figure 1. Structures of DPP and its corresponding proton/chargetransfer isomers, methylated derivatives, and analogues.

transfer vs charge transfer in 4-(dimethylamino)-1H-pyrrolo[2,3- $b]$ pyridine (DPP, see Figure 1). The results make DPP a unique model among hydrogen-bonded complexes to study the interplay between two fundamental mechanisms fine-tuned by solvent polarity as well as hydrogen-bonding perturbation. In this paper we have further performed comprehensive spectroscopic and dynamic studies on DPP and its relative derivatives, aimed at gaining a detailed insight into the electronic properties and corresponding relaxation dynamics. Ground-state thermodynamics as well as excited-state proton-transfer dynamics for DPP dimer and DPP/guest complexes have been deduced in nonpolar solvents. Detailed solvent-polarity-dependent studies in combination with semiempirical calculations led us to derive the excited-state charge-transfer properties such as dipole moment, orbital configuration, etc. Finally, both temperature and time dependent fluorescence spectroscopy and dynamics were performed to resolve the excited-state charge-versusproton-transfer dynamics.

\section{Experimental Section}

2.1. Materials. The synthesis of DPP was performed according to procedures used in previous reports with slight modification. ${ }^{36-38}$ Brief methodology and spectral characterization in each step for synthesizing DPP and related derivatives are described below. For clarity, structures of DPP and its corresponding analogues are depicted in Figure 1.

7-Hydroxy-1H-pyrrolo[2,3-b]pyridinium m-Chlorobenzoate $\left(\mathrm{C}_{14} \mathrm{H}_{11} \mathrm{ClN}_{2} \mathrm{O}_{3}\right)$ (1). A $1.2 \mathrm{~g}(5.9 \mathrm{mmol})$ sample of $85 \%$ $m$-chloroperoxybenzoic acid was added to $0.5 \mathrm{~g}$ (4.23 $\mathrm{mmol})$ of $1 \mathrm{H}$-pyrrolo[2,3- $b$ ]pyridine dissolved in $15 \mathrm{~mL}$ of redistilled 1,2-dimethoxyethane The resulting solution was stirred at room temperature for $1.5 \mathrm{~h}$ and during this period the product gradually precipitated. The mixture was then cooled and the light yellow product was isolated by filtration and washed with diethyl ether to give $\mathbf{1}(0.45 \mathrm{~g}, \sim 75 \%)$.

1H-Pyrrolo[2,3-b]pyridine-7-oxide $\left(\mathrm{C}_{7} \mathrm{H}_{6} \mathrm{~N}_{2} \mathrm{O}\right)(2)$. A $1.0 \mathrm{~g}$ (3.4 mmol) sample of $\mathbf{1}$ in $10 \mathrm{~mL}$ of water was basified to $\mathrm{pH}$ $\sim 9$ with saturated $\mathrm{K}_{2} \mathrm{CO}_{3}$ solution, followed by the extraction of chloroform. The solution was then concentrated to obtain 2 . ${ }^{1} \mathrm{H}$ NMR $\left(200 \mathrm{MHz}, \mathrm{DMSO}-d_{6}\right) \delta 6.58(\mathrm{~d}, J=3.0 \mathrm{~Hz}, 1 \mathrm{H})$, $7.10(\mathrm{~d}, J=6.0 \mathrm{~Hz}, 1 \mathrm{H}), 7.48(\mathrm{~d}, J=3.0 \mathrm{~Hz}, 1 \mathrm{H}), 7.67(\mathrm{~d}, J$ $=8.0 \mathrm{~Hz}, 1 \mathrm{H}), 8.18(\mathrm{~d}, J=6.0 \mathrm{~Hz}, 1 \mathrm{H}), 13.50(\mathrm{~s}, 1 \mathrm{H}$, pyrrole $\mathrm{NH})$.

4-Chloro-1H-pyrrolo[2,3-b]pyridine $\left(\mathrm{C}_{7} \mathrm{H}_{5} \mathrm{ClN}_{2}\right)$ (3). A 0.5 $\mathrm{g}$ sample of $\mathbf{2}$ was added in portions to the cooled phosphoric trichloride solution $(5 \mathrm{~mL})$, and the mixture was refluxed for 5 h. Phosphoric trichloride was then distilled off under reduced pressure followed by the dilution of water $(5 \mathrm{~mL})$. The solution was basified with sodium carbonate to allow the precipitation for $\sim 1 \mathrm{~h}$. The precipitate was filtered off to obtain 3. ${ }^{1} \mathrm{H}$ NMR $\left(200 \mathrm{MHz}, \mathrm{DMSO}-d_{6}\right) \delta 6.55(\mathrm{~d}, J=3.4 \mathrm{~Hz}, 1 \mathrm{H}), 7.22(\mathrm{~d}, J=$ $5.1 \mathrm{~Hz}, 1 \mathrm{H}), 7.63(\mathrm{~d}, J=3.4 \mathrm{~Hz}, 1 \mathrm{H}), 8.23(\mathrm{~d}, J=5.1 \mathrm{~Hz}$, $1 \mathrm{H}), 10.25$ (s, 1H, pyrrole $\mathrm{NH}$ ).

4-(Dimethylamino)-1H-pyrrolo[2,3-b]pyridine $\left(C_{9} H_{11} N_{3}, D P P\right)$. A mixture of $\mathbf{3}(2 \mathrm{mmol})$ and dimethylammonium chloride (10 mmol) was heated in an oil bath at $180^{\circ} \mathrm{C}$ for $5 \mathrm{~h}$. After cooling, the dark brown reaction mixture was worked up by flash column chromatography (eluent: 10-20\% methanol by weight in dichloromethane) to obtain DPP. ${ }^{1} \mathrm{H}$ NMR $\left(200 \mathrm{MHz}, \mathrm{CDCl}_{3}\right)$ $\delta 3.27(\mathrm{~s}, 6 \mathrm{H}), 6.18(\mathrm{~d}, J=6.0 \mathrm{~Hz}, 1 \mathrm{H}), 6.64(\mathrm{~d}, J=3.8 \mathrm{~Hz}$, $1 \mathrm{H}), 7.12(\mathrm{~d}, J=3.8 \mathrm{~Hz}, 1 \mathrm{H}), 7.96(\mathrm{~d}, J=6.0 \mathrm{~Hz}, 1 \mathrm{H}), 11.8$ (s, 1H, pyrrole $\mathrm{NH})$.

1-Methyl-4-(dimethylamino)-1-H-pyrrolo[2,3-b]pyridine $\left(C_{10} H_{13} N_{3}, 1 M D P P\right)$. 1MDPP was synthesized by adding sodium hydride $(100 \mathrm{mg})$ to the THF solution containing DPP $(0.15$ $\mathrm{g})$, followed by the addition of methyl iodide $(100 \mathrm{mg})$. The resulting product, 1MDPP, was purified by column chromatography (eluent $1: 1 \mathrm{v} / \mathrm{v}$ hexanes: ethyl acetate). ${ }^{1} \mathrm{H}$ NMR $(200$ $\left.\mathrm{MHz}, \mathrm{CDCl}_{3}\right) \delta 3.28(\mathrm{~s}, 6 \mathrm{H}), 3.89(\mathrm{~s}, 3 \mathrm{H}), 6.20(\mathrm{~d}, J=6.0 \mathrm{~Hz}$, $1 \mathrm{H}), 6.62(\mathrm{~d}, J=3.6 \mathrm{~Hz}, 1 \mathrm{H}), 6.94(\mathrm{~d}, J=3.6 \mathrm{~Hz}, 1 \mathrm{H}), 8.03$ $(\mathrm{d}, J=6 \mathrm{~Hz}, 1 \mathrm{H})$.

7-Methyl-4-(dimethylamino)-1H-pyrrolo[2,3-b]pyridine $\left(C_{10} H_{13} N_{3}, 7 M D P P\right)$. 7MDPP was synthesized by the reaction of DPP $(0.1 \mathrm{~g})$ and methyl iodide $(0.5 \mathrm{~g})$ in THF under $\mathrm{N}_{2}$ atmosphere. $\mathrm{NaOH}(2.5 \mathrm{~N}, 10 \mathrm{~mL})$ was then added, and the mixture was stirred for $\sim 20 \mathrm{~min}$ to obtain crude $7 \mathrm{MDPP}$. The product was further purified by column chromatography (eluent: ethyl acetate and then methanol). ${ }^{1} \mathrm{H} \mathrm{NMR}\left(\mathrm{CDCl}_{3}, 400\right.$ $\mathrm{MHz}) \delta 3.38(\mathrm{~s}, 6 \mathrm{H}), 4.08(\mathrm{~s}, 3 \mathrm{H}), 6.05(\mathrm{~d}, J=7.2 \mathrm{~Hz}, 1 \mathrm{H})$, $6.76(\mathrm{~d}, J=2.8 \mathrm{~Hz}, 1 \mathrm{H}), 7.35(\mathrm{~d}, J=7.2 \mathrm{~Hz}, 1 \mathrm{H}), 7.47$ (d, $J$ $=2.8 \mathrm{~Hz}, 1 \mathrm{H})$.

4-Amino-1H-pyrrolo[2,3-b]pyridine $\left(\mathrm{C}_{7} \mathrm{H}_{7} \mathrm{~N}_{3}, \mathrm{APP}\right)$. APP was prepared according to a previously reported procedure ${ }^{39}$ Briefly, a mixture of $0.2 \mathrm{~g}(1.11 \mathrm{mmol})$ of 4-nitro-1H-pyrrolo[2,3-b]pyridine-7-oxide ${ }^{40,41}$ and $0.8 \mathrm{~g}$ of Fe powder in $8 \mathrm{~mL}$ of glacial acetic acid was heated with stirring at $100{ }^{\circ} \mathrm{C}$ for $2 \mathrm{~h}$. The cooled mixture was diluted with $20 \mathrm{~mL}$ of water, adjusted to $\mathrm{pH} \sim$ 10-11 with $\mathrm{NaOH}$, and then continuously extracted with diethyl ether $(\sim 250 \mathrm{~mL})$. The extract was dried over anhydrous $\mathrm{Na}_{2}-$ $\mathrm{SO}_{4}$ and then evaporated on a rotary evaporator to obtain APP. ${ }^{1} \mathrm{H}$ NMR $\left(200 \mathrm{MHz}, \mathrm{DMSO}-d_{6}\right) \delta 6.48(\mathrm{~d}, J=7.0 \mathrm{~Hz}, 1 \mathrm{H})$, $6.82(\mathrm{~d}, J=3.0 \mathrm{~Hz}, 1 \mathrm{H}), 7.28(\mathrm{~d},=\mathrm{J} 3.0 \mathrm{~Hz}, 1 \mathrm{H}), 7.87(\mathrm{~d}, J$ $=7.0 \mathrm{~Hz}, 1 \mathrm{H}), 12.03(\mathrm{~s}, 1 \mathrm{H}$, pyrrole $\mathrm{NH})$.

Various solvents are of spectrograde quality (Merck, Inc.) and used right after received. 2-Methyltetrahydrofuran (2MTHF) and acetonitrile showed traces of fluorescence impurities and were fractionally distilled prior to use.

2.2. Measurements. Steady-state absorption and emission spectra were recorded by a Varian (Cary 3E) UV-vis spectrophotometer and a Hitachi (F4500) fluorimeter, respectively. Both wavelength-dependent excitation and emission response of the fluorimeter have been calibrated according to a previously reported method. ${ }^{31 \mathrm{~b}}$ Room-temperature fluorescence quantum yields were measured using quinine sulfate/1.0 $\mathrm{N} \mathrm{H}_{2} \mathrm{SO}_{4}$ as 
reference, assuming a yield of 0.564 with 365 -nm excitation. ${ }^{42}$ For the temperature-dependent emission measurement a 3rd harmonic of the $\mathrm{Nd}$ :YAG laser $(355 \mathrm{~nm}, 8 \mathrm{~ns}$ duration, Continuum Surlite II) pumped optical parametric oscillator (OPO) served as a light source. The output of the fundamental laser frequencies was then frequency doubled by a BBO crystal to obtain tunable excitation frequencies between 270 and 320 $\mathrm{nm}$. The emission was collected at a right angle with respect to the excitation source and detected by an intensified charge coupled detector (ICCD, Princeton Instrument, Model 576G/ 1). Typically, 100 laser shots were collected and averaged in each data acquisition period. Low-temperature measurements were performed in an Oxford cryostat (Model CCC1104) with temperature regulator (Model ITC502).

Pico-nanosecond lifetime measurements were achieved by using either a second $(380-420 \mathrm{~nm})$ or third $(260-275 \mathrm{~nm})$ harmonic of the femtosecond $\mathrm{Ti}-$ Sapphire oscillator $(82 \mathrm{MHz}$, Spectra Physics) as an excitation source coupled with a pulse picker (NEOS, model N17389). This combination gives an output repetition rate of $8 \mathrm{MHz}$ to avoid the accumulation of residue from the previous excitation pulse due to the longer fluorescence decay components. An Edinburgh OB 900-L timecorrelated single photon counter was used as a detecting system. Since the fwhm of the excitation pulse is typically $\sim 100 \mathrm{fs}$, the resolution is limited by the detector response of $\sim 30 \mathrm{ps}$. The fluorescence decays were analyzed by the sum of exponential functions with an iterative convolution method reported previously. ${ }^{42}$ This procedure should allow partial removal of the instrument time broadening and consequently renders a temporal resolution of $\sim 15 \mathrm{ps}$.

Detailed methods of the theoretical approach (e.g. 6-31G(d, p) and higher levels) for the thermodynamics of HB complexes in the ground state have been described previously. ${ }^{43}$ For calculating the physical parameters such as dipole moment, cavity radius, etc., of DPP, various methods including AM1, PM3, or MP2/6-31G(d, p) were applied. The complexity of molecular structure makes an ab initio approach in the excited state extremely time consuming and in some cases even not feasible. Instead, the properties of various low-lying excited singlet states were estimated by an INDO/S-CI calculation based on an AM1 geometry optimized ground-state structure. All singly excited configurations from the 15 highest occupied to the 15 lowest unoccupied (225 configurations) molecular orbitals were involved in the computation.

The following sections are organized according to a sequence of steps where we first performed detailed absorption and fluorescence titration experiments to determine the thermodynamics and ESDPT properties of DPP self-dimerization and hydrogen-bonding complexes in nonpolar solvents. Subsequently, dual emission properties of DPP in polar, aprotic solvents were investigated and discussed on the basis of the excited-state charge-transfer property. Finally, the differentiation between solvent diffusive reorganization and solvent relaxation to affect the solvent assisted ESDPT dynamics in alcohols was elaborated.

\section{Results}

3.1. Hydrogen-Bonding Association in Nonpolar Solvents. When the concentration was prepared to be as low as $9.2 \times$ $10^{-6} \mathrm{M}$, DPP exhibits the lowest singlet $\pi \rightarrow \pi^{*}$ absorption band maximum at $303 \mathrm{~nm}\left(\epsilon_{303} \sim 6750 \mathrm{M}^{-1} \mathrm{~cm}^{-1}\right)$. The spectral feature is similar to that of 1MDPP (see Figure 2) generally treated as a nonproton-transfer model due to the lack of the pyrrolic $\mathrm{N}-\mathrm{H}$ proton. Thus, the assignment of the $303-\mathrm{nm}$ band

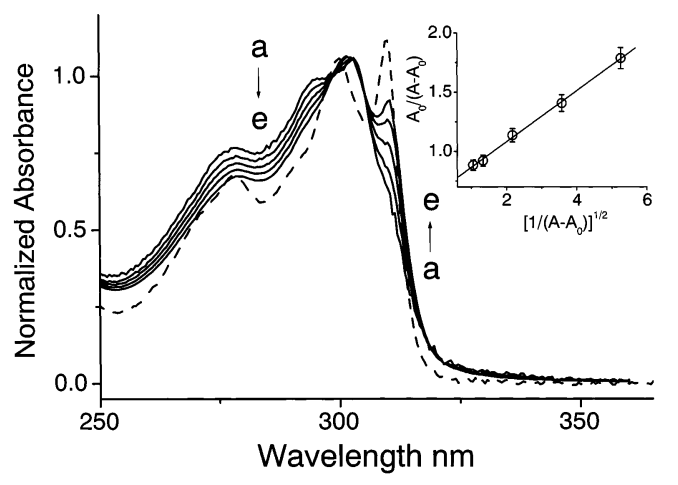

Figure 2. (-) The concentration-dependent absorption spectra of DPP in cyclohexane, in which DPP $\left(\mathrm{C}_{0}\right)$ was prepared at (a) $1.1 \times 10^{-4}$, (b) $2.1 \times 10^{-4}$, (c) $4.3 \times 10^{-4}$, (d) $8.6 \times 10^{-4}$, (e) $1.7 \times 10^{-3} \mathrm{M}$. The absorption spectra are normalized at $305 \mathrm{~nm}$. (--) The absorption spectrum of 1MDPP $\left(1.0 \times 10^{-5} \mathrm{M}\right)$ in cyclohexane. Insert: Plot of $A_{0} /\left(A-A_{0}\right)$ versus $\sqrt{1 /\left(A-A_{0}\right)}$ at $310 \mathrm{~nm}$ for $\mathrm{b}-\mathrm{e}$ and a best linear least-squares fitting curve using eq d. See section 3.1 for the definition of $A_{0}$ and $A$.

to the amine-like monomer species is unambiguous. Upon increasing the concentration, changes in the spectral features were observed in which the spectra reveal red shift with the appearance of a new $0-0$ onset peak maximum at $310 \mathrm{~nm}$ (see Figure $2 \mathrm{a}-\mathrm{e}$ ). In comparison, the absorption features of 1MDPP in cyclohexane reveal concentration independence. Since the difference between DPP and 1MDPP lies in the dual hydrogenbonding sites in DPP, the results unambiguously conclude the formation of DPP dimer and/or higher-order aggregates in cyclohexane through the dual hydrogen-bonding effect. Similar to that proposed in the 7AI self-association,,$^{3,26 b-d}$ we first assume a dominant self-dimerization form possibly possessing a cyclic type of hydrogen bonding configuration where the dual hydrogen-bonding sites, i.e., the $\mathrm{N}(1) \mathrm{H}$ hydrogen and the pyridinic nitrogen in DPP (i.e., $\mathrm{N}(7)$ ), act as a proton donor and acceptor, respectively. Consequently, a competitive equilibrium between DPP monomer and its corresponding selfassociation is established, and the dimerization constant $K_{\mathrm{a}}$ can be expressed as

$$
K_{\mathrm{a}}=\frac{C_{\mathrm{p}}}{\left(C_{0}-2 C_{\mathrm{p}}\right)^{2}}
$$

where $\mathrm{C}_{0}$ is the initial concentration of DPP, and $C_{\mathrm{p}}$ denotes the concentration of the DPP dimeric form. In the case of 7AI and its corresponding analogues, significant red shift of the absorption spectrum near the onset of the monomer $S_{0} \rightarrow S_{1}$ $\left(\pi \pi^{*}\right)$ absorption is commonly observed upon dimerization. ${ }^{1-3,31-34}$ For instance, the absorbance at wavelengths of $>310 \mathrm{~nm}$ can be exclusively attributed to the dimeric absorption of $7 \mathrm{AI}^{3}$ On the the basis of the Beer-Lambert law, eq a can thus be rewritten as

$$
\frac{C_{0}}{A}=\sqrt{\frac{1}{\epsilon_{\mathrm{D}}}} \sqrt{\frac{1}{K_{\mathrm{a}}}} \sqrt{\frac{1}{A}}+\frac{2}{\epsilon_{\mathrm{D}}}
$$

where $A$ and $\epsilon_{\mathrm{D}}$ denote the absorbance (in the $1 \mathrm{~cm}$ path-length cell) and the molar extinction coefficient of the dimer, respectively, at a selected wavelength. According to the plot of $C_{0} / A$ as a function of $\sqrt{1 / A}, K_{\mathrm{a}}$ can then be deduced by the ratio for the intercept versus the square of the slope.

For the case of DPP, however, significant overlaps between monomeric and dimeric species were observed throughout the concentration-dependent UV-vis absorption measurement. As 
a result, upon considering the absorbance attributed to both monomer and dimer at any selected wavelength, modification of eq $b$ is necessary. A revised equation of $b$ with an arbitrary cell path length of $\lambda$ has been deduced and expressed as

$$
\begin{aligned}
\frac{C_{0} l}{A-\epsilon_{\mathrm{M}} C_{0} l} & = \\
& \sqrt{\frac{l}{\epsilon_{\mathrm{D}}-2 \epsilon_{\mathrm{M}}}} \cdot \sqrt{\frac{1}{K_{\mathrm{a}}}} \sqrt{\frac{1}{A-\epsilon_{\mathrm{M}} C_{0} l}}+\frac{2}{\epsilon_{\mathrm{D}}-2 \epsilon_{\mathrm{M}}} \text { (c) }
\end{aligned}
$$

No assumption is made in eq c except that the value of the molar extinction coefficient of the monomer $\epsilon_{\mathrm{M}}$, at the analyzed wavelength needs to be obtained prior to the deduction of $K_{\mathrm{a}}$ value. Multiplying $\epsilon_{\mathrm{M}}$ on both sides, eq $\mathrm{c}$ can be further simplified to

$$
\frac{A_{0}}{A-A_{0}}=\sqrt{\frac{l \epsilon_{\mathrm{M}}{ }^{2}}{\epsilon_{\mathrm{D}}-2 \epsilon_{\mathrm{M}}}} \sqrt{\frac{1}{K_{\mathrm{a}}}} \cdot \sqrt{\frac{1}{A-A_{0}}}+\frac{2 \epsilon_{\mathrm{M}}}{\epsilon_{\mathrm{D}}-2 \epsilon_{\mathrm{M}}}
$$

where $A_{0}$ in eq $\mathrm{d}$ simply denotes the absorbance of the monomer at the selected wavelength, assuming that no dimer is formed at the prepared concentration. $A_{0}$ can be obtained by performing the concentration dependent study at a sufficiently low concentration so that monomer exists predominantly (e.g., $9.2 \times$ $10^{-6} \mathrm{M}$ in the case of DPP). By knowing the proportionality of the dilution, $A_{0}$ values can thus be obtained in each prepared concentration. In this study, the wavelength at $310 \mathrm{~nm}$ was selected due to the relatively higher absorptivity upon dimerization (vide infra). Under a sufficiently low concentration where only monomer exists, $\epsilon_{\mathrm{M}}^{310}$ was measured to be ca. 2835 $\mathrm{M}^{-1} \mathrm{~cm}^{-1}$. A plot of $A_{0} /\left(A-A_{0}\right)$ at $310 \mathrm{~nm}$ as a function of $\sqrt{1 /\left(A-A_{0}\right)}$ shown in insert of Figure 2 reveals sufficiently linear behavior, supporting the assumption of dimeric formation in concentrated DPP. Accordingly, by fixing the $\epsilon_{\mathrm{M}}$ and $l(=$ $1.0 \mathrm{~cm}$ ) values, the best linear least-squares fit using eq $\mathrm{d}$ to the insert of Figure 2 gives $\epsilon_{\mathrm{D}}^{310}$ and $K_{\mathrm{a}}$ values to be $(1.4 \pm 0.2)$ $\times 10^{4} \mathrm{M}^{-1} \mathrm{~cm}^{-1}$ and $(4.2 \pm 0.4) \times 10^{3} \mathrm{M}^{-1}$, respectively. Knowing that one dimer actually consists of two DPP chromophores, the extinction coefficient for each DPP in the dimeric form is thus deduced to be $\epsilon_{\mathrm{D}}^{310} / 2 \sim 7100 \mathrm{M}^{-1} \mathrm{~cm}^{-1}$. In comparison to that of the $7 \mathrm{AI}$ dimer $\left(K_{\mathrm{a}} \sim 2.2 \times 10^{3} \mathrm{M}^{-1}\right.$ in cyclohexane $\left.{ }^{26 \mathrm{~d}}\right)$, the higher dimerization constant in DPP may be rationalized by increasing the basicity of the pyridinic nitrogen resonantly enhanced by the electron donating property of the para-dimethylamino functional group (vide infra). This viewpoint can be further supported by adding acetic acid as the guest molecule, forming a DPP/acetic acid dual hydrogenbonded complex.

Figure 3 shows the absorption spectra of DPP as a function of the acetic acid concentration in cyclohexane, in which the initial concentration of DPP $C_{0}$ was prepared to be as low as $1.2 \times 10^{-5} \mathrm{M}$ to avoid self-dimerization. The formation of DPP/ acetic acid hydrogen-bonded complexes is clearly shown by the growth of an absorption band at $\sim 310$ accompanied by the appearance of an isosbestic point at ca. $295 \mathrm{~nm}$ throughout the titration, indicating the existence of equilibrium with a common intermediate. In comparison, although 1MDPP provides two hydrogen-bonding sites, i.e., the pyridinic and dimethylamino nitrogen, negligible spectral changes were observed upon adding acetic acid up to $10^{-3} \mathrm{M}$. The result unambiguously supports the formation of a 1:1 DPP/acetic acid complex incorporating cyclic dual hydrogen bonds at N(1)H and N(7) positions. Similar to that observed in the concentration-dependent study the acetic

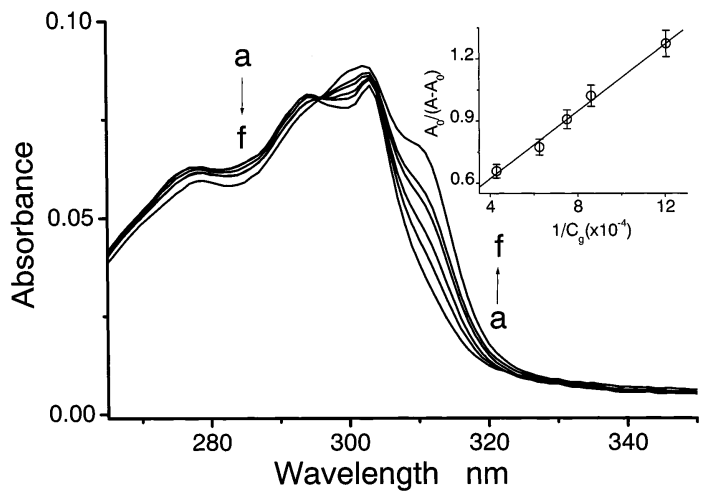

Figure 3. The absorption spectra of DPP $\left(8.0 \times 10^{-6} \mathrm{M}\right.$ in cyclohexane) as a function of free acetic acid concentration $C_{\mathrm{g}}$ of (a) 0 , (b) $8.3 \times 10^{-6}$, (c) $1.2 \times 10^{-5}$, (d) $1.5 \times 10^{-5}$, (e) $2.0 \times 10^{-5}$, (f) $2.5 \times 10^{-5} \mathrm{M}$. Insert: The plot of $A_{0} /\left(A-A_{0}\right)$ at $310 \mathrm{~nm}$ as a function of $1 / C_{\mathrm{g}}$ in curves $\mathrm{b}-\mathrm{f}$ and a best least-squares fitting curve using eq e.

acid absorption titration spectra reveal significant overlap between uncomplexed DPP monomer and 1:1 DPP/acetic acid hydrogen-bonded complex. In consideration of self-dimerization for acetic acid the competitive equilibrium can be expressed as

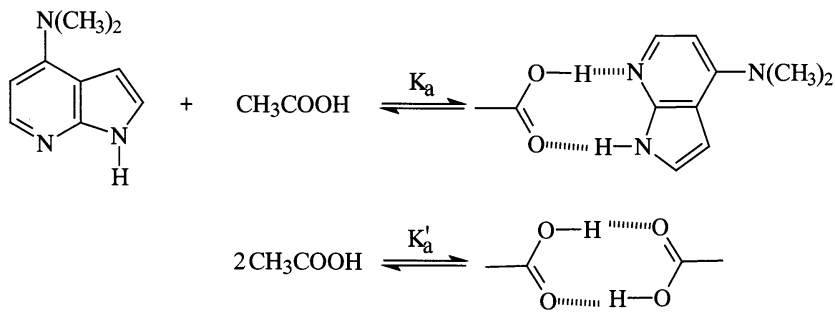

In the above expression, the possibility of a single hydrogen bonding formation between $\operatorname{DPP}\left(\mathrm{N}\left(\mathrm{CH}_{3}\right)_{2}\right)$ site and acetic acid is neglected due to its rather small association constant. Since DPP is complexed by stoichiometrically equivalent guest molecules (e.g., acetic acid), while acetic acid is in excess, the relationship between the measured absorbance as a function of the free acetic acid concentration $C_{\mathrm{g}}$ can be expressed by

$$
\frac{A_{0}}{A-A_{0}}=\frac{\epsilon_{\mathrm{M}}}{\epsilon_{\mathrm{M}}-\epsilon_{\mathrm{C}}}\left(\frac{1}{K_{\mathrm{a}} C_{\mathrm{g}}}+1\right)
$$

where $\epsilon_{\mathrm{M}}$ and $\epsilon_{\mathrm{C}}$ in eq e denote molar extinction coefficients of DPP monomer and the hydrogen-bonded complex, respectively, at a specific wavelength. On the basis of the negligible consumption of acetic acid upon forming the DPP/acetic acid complex, $C_{\mathrm{g}}$ can be deduced independently by the selfassociation equation of the acetic acid; namely,

$$
C_{\mathrm{g}}=C_{\mathrm{g}}{ }^{0}-\left[\frac{\left(4 K_{\mathrm{a}}^{\prime} C_{\mathrm{g}}{ }^{0}+1\right)-\sqrt{8 K_{\mathrm{a}}^{\prime} C_{\mathrm{g}}{ }^{0}+1}}{4 K_{\mathrm{a}}^{\prime}}\right]
$$

where $C_{\mathrm{g}}{ }^{0}$ is the initially prepared acetic acid concentration. The self-association constant $K_{\mathrm{a}}^{\prime}$ of acetic acid has been reported to be $3.7 \times 10^{4} \mathrm{M}^{-144}$ in $n$-heptane, which was used in the case of cyclohexane due to their similar solvent polarity. A straight-line plot of $A_{0} /\left(A-A_{0}\right)$ as a function of $1 / C_{g}$ at a selected wavelength of $310 \mathrm{~nm}$ (see insert of Figure 3 ) supports the validity of the assumption of a 1:1 DPP/acetic acid complex formation. Consequently, a best linear least-squares fit using eq e deduces $K_{\mathrm{a}}$ to be $(5.2 \pm 0.5) \times 10^{4} \mathrm{M}^{-1}$ which is approximately twice as large as that of the 7AI/acetic acid 


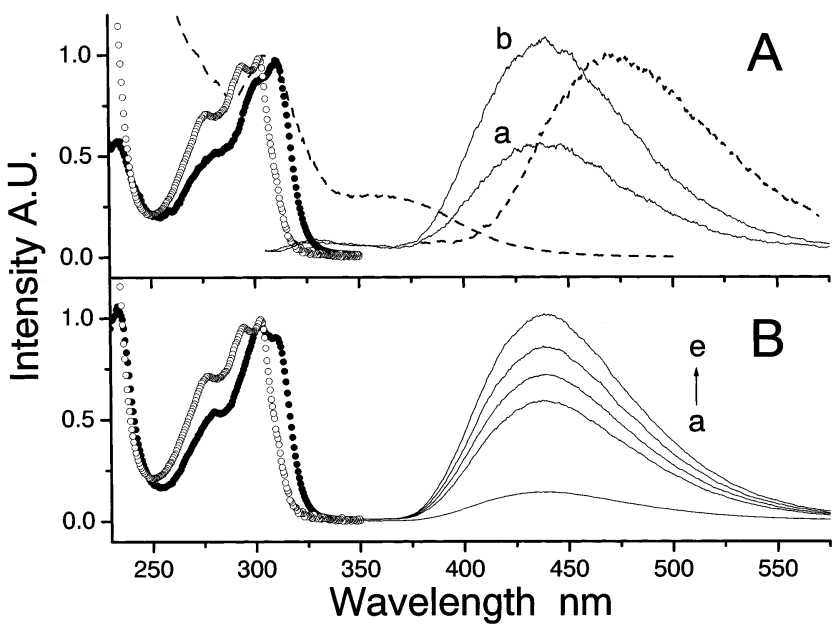

Figure 4. A. The fluorescence spectra of DPP in cyclohexane where DPP was prepared at (a) $4.2 \times 10^{-5}$ and (b) $6.5 \times 10^{-5} \mathrm{M}$. Spectra was normalized at $330 \mathrm{~nm}$. The excitation spectra $\left(6.5 \times 10^{-5} \mathrm{M}\right)$ monitored at (००) 340 and (••) $500 \mathrm{~nm}$. (- -) Absorption and emission spectra of 7MDPP in cyclohexane. B. The fluorescence spectra of DPP $\left(8.0 \times 10^{-6} \mathrm{M}\right.$ in cyclohexane $)$ as a function of the acetic acid concentration of (a) $2.0 \times 10^{-6}$, (b) $8.30 \times 10^{-6}$, (c) $1.20 \times 10^{-5}$, (d) $1.33 \times 10^{-5}$, (e) $1.65 \times 10^{-5} \mathrm{M}$. The excitation spectra of $\mathrm{c}$ monitored at $(\circ \circ) 340$ and $(\cdot) 500 \mathrm{~nm}$.

complex $\left(\sim 2.2 \times 10^{4} \mathrm{M}^{-1}\right),{ }^{26 \mathrm{~d}}$ further supporting the proposed stronger proton-accepting property on the pyridinic nitrogen.

The fluorescence spectra of DPP in cyclohexane reveal strong concentration dependence (see Figure 4A). At sufficiently low concentrations where the monomer mainly exists in the equilibrium, a very weak, normal Stokes shifted emission maximum at $\sim 327 \mathrm{~nm}$ was observed (the $\mathrm{F}_{\mathrm{N}}$ band, $\Phi_{\mathrm{f}} \sim 9.24 \times 10^{-4}$ ). Upon increasing the concentration, a large Stokes-shifted emission maximum at $440 \mathrm{~nm}$ (the $\mathrm{F}_{\mathrm{T}}$ band) gradually appears. Different excitation spectral features were obtained upon monitoring at $\mathrm{F}_{\mathrm{N}}$ and $\mathrm{F}_{\mathrm{T}}$ bands where the excitation spectrum of the $\mathrm{F}_{\mathrm{T}}$ band is red shifted by $\sim 10 \mathrm{~nm}$ with respect to that of the $F_{N}$ band. The rise time of both emission bands cannot be resolved by our current photon counting system with a response limit of $\sim 15 \mathrm{ps}$. The results in combination with resolvable, different relaxation dynamics for $\mathrm{F}_{\mathrm{N}}\left(\tau_{\mathrm{obs}} \sim 70 \mathrm{ps}\right)$ and $\mathrm{F}_{\mathrm{T}}\left(\tau_{\mathrm{obs}}\right.$ $\sim 2.8 \mathrm{~ns}$ ) bands unambiguously conclude that they originate from different ground-state species and one cannot be the precursor of the other. In comparison, 1MDPP, which is considered a nonproton-transfer model compound, exhibits a concentration independent, normal Stokes-shifted emission maximum at $328 \mathrm{~nm}\left(\tau_{\mathrm{f}} \sim 85 \mathrm{ps} ; \Phi_{\mathrm{f}} \sim 1.36 \times 10^{-3}\right)$. On the other hand, 7MDPP, the analogue of proton-transfer tautomer for DPP, reveals a single fluorescence band maximum at 470 $\mathrm{nm}$ in cyclohexane $\left(\tau_{\mathrm{f}} \sim 4.1 \mathrm{~ns} ; \Phi_{\mathrm{f}} \sim 9.8 \times 10^{-2}\right)$. It is thus conceivable to conclude that the $\mathrm{F}_{\mathrm{N}}$ band is ascribed exclusively to the monomer emission, while the $\mathrm{F}_{\mathrm{T}}$ band with a Stokes shift (peak-to-peak) of $\sim 7850 \mathrm{~cm}^{-1}$ can be unambiguously assigned to the tautomer emission resulting from ESDPT of the DPP dimer.

Upon exciting the DPP/acetic acid complex, a similar ESDPT reaction was observed, resulting in a proton-transfer tautomer emission $\left(\lambda_{\max } \sim 440 \mathrm{~nm}\right)$ of which the excitation spectrum is red shifted by $\sim 10 \mathrm{~nm}$ with respect to the uncomplexed monomer (see Figure 4B). The emission monitored at $>430$ $\mathrm{nm}$ exhibits a single-exponential decay rate $\left(\tau_{\mathrm{obs}} \sim 5.2 \mathrm{~ns}\right)$ accompanied by system response limited rise dynamics (i.e., $\left.k_{\mathrm{pt}}>6.7 \times 10^{10} \mathrm{~s}^{-1}\right)$. The results unambiguously demonstrate that in nonpolar solvents both catalytic (acetic acid) and

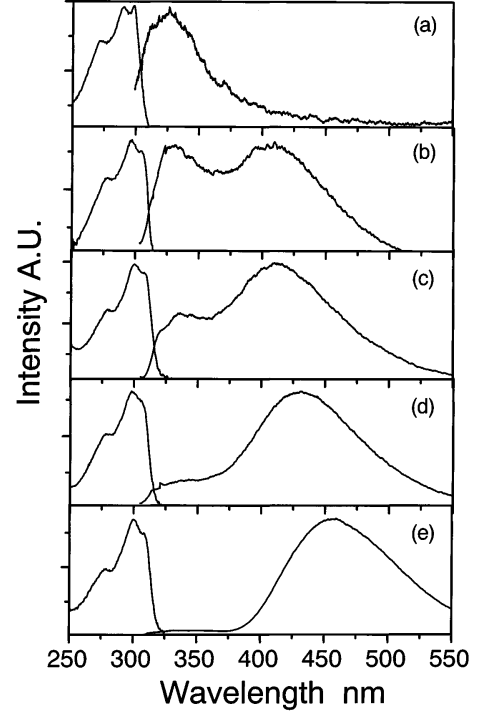

Figure 5. The fluorescence spectra of DPP in various solvents: (a) ethyl ether (34.5), (b) ethyl acetate (38.1), (c) dichloromethane (40.7), (d) acetonitrile (45.6), (e) ethanol (51.9). $E_{\mathrm{T}}(30)$ value in $\mathrm{kcal} / \mathrm{mol}$ for each solvent is specified in parentheses. The excitation wavelength is $290 \mathrm{~nm}$.

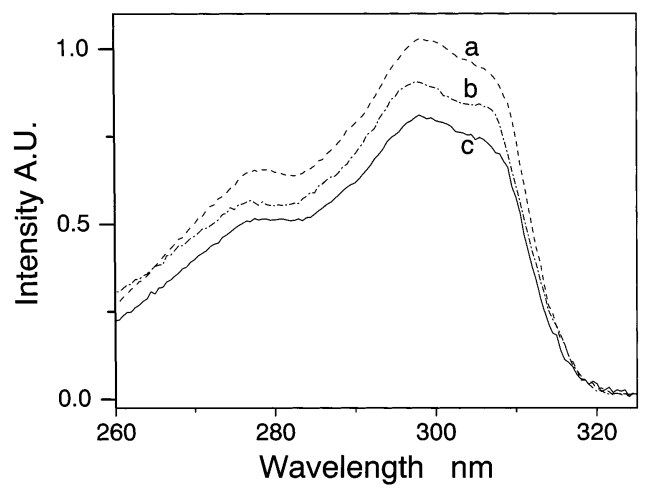

Figure 6. The excitation spectra of DPP $\left(1.5 \times 10^{-5} \mathrm{M}\right)$ in ethyl acetate monitored at (a) (-) $500 \mathrm{~nm}$, (b) $(-\cdot) 340 \mathrm{~nm}$, and (c) (-) the absorption spectrum.

noncatalytic (dimer) types ${ }^{26 c}$ of ultrafast ESDPT take place in DPP dual hydrogen-bonded complexes.

3.2. In Polar, Aprotic Solvents. In contrast to the large selfassociation for DPP in cyclohexane, both absorption and emission spectra reveal concentration independence within the studied concentrations of $10^{-6}-10^{-3} \mathrm{M}$ in all polar, aprotic solvents. The results can be rationalized by the large (polar) solvent stabilization energy for the solvated DPP monomer, preventing self-association or even higher-order aggregation. However, unlike the single, solvent-polarity-dependent Stokesshifted emission observed in $7 \mathrm{AI},{ }^{45}$ remarkable dual emission was observed for DPP in polar, aprotic solvents (Figure 5). These two emission bands, specified as $F_{N}$ and $F_{C}$ (the longwavelength band) originating from a common ground-state species, are ascertained by the same fluorescence excitation spectra of DPP in, e.g., ethyl acetate (see Figure 6). The excitation spectra, within experimental error, are also identical with the absorption spectrum, indicating that both emissions result from a common Franck-Condon excited state. In contrast to the nearly solvent-independent absorption maximum, peak frequencies for both $\mathrm{F}_{\mathrm{N}}$ and $\mathrm{F}_{\mathrm{C}}$ bands reveal solvent-polarity dependence, decreasing as the empirical parameter of solventpolarity $E_{\mathrm{T}}(30)$ increases (see Figure 5 and Table 1). For example, the peak frequency of the $\mathrm{F}_{\mathrm{N}}$ band is red shifted by $\sim$ 
TABLE 1: Physical Parameters of Solvents as Well as Photophysical Properties of DPP, 1MDPP, and 7MDPP in Various Solvents at Room Temperature

\begin{tabular}{|c|c|c|c|c|c|c|c|c|c|c|c|c|}
\hline \multirow[b]{2}{*}{ solvent $^{a}$} & \multirow{2}{*}{$\begin{array}{c}E_{\mathrm{T}}(30) \\
\mathrm{kcal} / \mathrm{mol}\end{array}$} & \multirow[b]{2}{*}{$\Delta f$} & \multicolumn{4}{|c|}{$\left(\times 10^{4} \mathrm{~cm}^{-1}\right)\left(\times 10^{-3}\right)$} & \multirow{2}{*}{$\frac{\left(\times 10^{-3}\right)}{\Phi_{\mathrm{F}_{\mathrm{N}}}}$} & \multirow[b]{2}{*}{$\Phi_{\mathrm{F}_{\mathrm{C}}}$} & \multirow{2}{*}{$\frac{\left(\times 10^{-2}\right)}{\Phi_{\mathrm{F}_{\mathrm{T}}}}$} & \multirow{2}{*}{$\begin{array}{l}\tau_{\mathrm{F}_{\mathrm{N}}} \\
(\mathrm{ns})\end{array}$} & \multirow{2}{*}{$\begin{array}{l}\tau_{\mathrm{F}_{\mathrm{C}}} \\
(\mathrm{ns})\end{array}$} & \multirow{2}{*}{$\begin{array}{l}\tau_{\mathrm{F}_{\mathrm{T}}} \\
(\mathrm{ns})\end{array}$} \\
\hline & & & $\tilde{\mathbf{v}}_{\mathrm{abs}}$ & $\tilde{\mathrm{v}}_{\mathrm{F}_{\mathrm{N}}}$ & $\tilde{\mathrm{v}}_{\mathrm{F}_{\mathrm{C}}}$ & $\tilde{\mathrm{V}}_{\mathrm{F}_{\mathrm{T}}}$ & & & & & & \\
\hline & & & & & & DPP & & & & & & \\
\hline CHE & 30.9 & 0 & 3.300 & 3.054 & & 2.272 & 0.92 & & 10.31 & 0.070 & 0.45 & 2.80 \\
\hline ether & 34.5 & 0.1684 & 3.286 & 3.042 & 2.500 & & 2.19 & 1.10 & & 0.102 & 0.31 & \\
\hline EA & 38.1 & 0.1997 & 3.278 & 3.037 & 2.457 & & 1.31 & 2.30 & & 0.080 & 0.35 & \\
\hline DCM & 40.7 & 0.2184 & 3.250 & 2.998 & 2.392 & & 2.68 & 6.70 & & 0.120 & 0.51 & \\
\hline $\mathrm{ACN}$ & 45.6 & 0.3062 & 3.248 & 2.985 & 2.325 & & 2.37 & 20.8 & & 0.110 & 2.30 & \\
\hline $\mathrm{EtOH}$ & 51.9 & 0.2890 & 3.234 & 2.990 & & 2.183 & 2.08 & & 6.67 & 0.050 & & $0.22^{b}$ \\
\hline $\mathrm{MeOH}$ & 55.4 & 0.3095 & 3.242 & 2.982 & & 2.175 & 1.01 & & 2.74 & 0.042 & & $\begin{array}{l}3.60 \\
0.17^{b} \\
3.17\end{array}$ \\
\hline CHE & 30.9 & 0 & 3.229 & 3.043 & NA & 1MDPP & 1.36 & & & 0.085 & & \\
\hline ether & 34.5 & 0.1684 & 3.223 & 3.038 & 2.514 & & 1.81 & 0.70 & & 0.095 & 0.15 & \\
\hline EA & 38.1 & 0.1997 & 3.219 & 3.001 & 2.471 & & 2.60 & 1.00 & & 0.128 & 0.18 & \\
\hline DCM & 40.7 & 0.2184 & 3.190 & 2.984 & 2.405 & & 3.11 & 1.50 & & 0.131 & 0.22 & \\
\hline $\mathrm{ACN}$ & 45.6 & 0.3062 & 3.200 & 2.980 & 2.331 & & 3.07 & 6.50 & & 0.162 & 1.18 & \\
\hline EtOH & 51.9 & 0.2890 & 3.179 & 2.981 & 2.262 & & 2.50 & 6.80 & & 0.055 & 1.33 & \\
\hline $\mathrm{MeOH}$ & 55.4 & 0.3095 & 3.183 & 2.972 & 2.212 & & 1.70 & 4.90 & & 0.048 & 1.05 & \\
\hline & & & & & & 7MDPP & & & & & & \\
\hline CHE & 30.9 & 0 & 2.759 & 2.119 & & & 98.0 & & & 4.065 & & \\
\hline EA & 38.1 & 0.1997 & 2.813 & 2.146 & & & 97.0 & & & 4.258 & & \\
\hline DCM & 40.7 & 0.2184 & 2.829 & 2.148 & & & 137 & & & 4.618 & & \\
\hline $\mathrm{ACN}$ & 45.6 & 0.3062 & 2.837 & 2.150 & & & 108 & & & 4.121 & & \\
\hline $\mathrm{EtOH}$ & 51.9 & 0.2890 & 2.845 & 2.174 & & & 87.0 & & & 3.405 & & \\
\hline
\end{tabular}

${ }^{a}$ CHE: cyclohexane. EA: ethyl acetate. DCM: dichloromethane. ACN: acetonitrile. ${ }^{b}$ The rise time.

$550 \mathrm{~cm}^{-1}$ from ethyl ether to acetonitrile, while it is as large as $1745 \mathrm{~cm}^{-1}$ for the $\mathrm{F}_{\mathrm{C}}$ band. In a comparative study the protontransfer tautomer analogue 7MDPP exhibits a normal fluorescence band, of which the peak frequency reveals slight solventpolarity dependence, being $21,187 \mathrm{~cm}^{-1}(470 \mathrm{~nm})$ in cyclohexane and $21500 \mathrm{~cm}^{-1}(465 \mathrm{~nm})$ in acetonitrile (see Table 1). The drastic difference in spectral properties between 7MDPP emission and the $\mathrm{F}_{\mathrm{C}}$ band of DPP in combination with the lack of solvent proton donating site to assist the proton-transfer reaction lead us to exclude the assignment of the $\mathrm{F}_{\mathrm{C}}$ band in polar, aprotic solvents to a proton-transfer tautomer emission.

Perhaps the strongest support for this viewpoint is given by 1MDPP; a nonproton- transfer model for DPP. 1MDPP revealed similar dual emission and solvent-polarity-dependent spectralshifted properties (see Figure 7 and Table 1) although the relative intensity between $F_{N}$ and $F_{C}$ bands is different from that observed in DPP (see Figures 5 and 7 for comparison). In consideration of the low ionization energy for the dimethylamino substituents, the results lead us to propose that the $\mathrm{F}_{\mathrm{C}}$ band originates from an excited-state intramolecular charge transfer (ESICT) reaction incorporating dimethylamine (electron donor) and pyridine ring (electron acceptor) in DPP. Further verification of the charge transfer emission can also be given by the synthesis of APP (see Figure 1) in which only the $\mathrm{F}_{\mathrm{N}}$ band was observed in various polar, aprotic solvents studied. For instance, APP exhibited single, normal Stokes shifted emission band maxima at $\sim 335$ and $343 \mathrm{~nm}$ in $\mathrm{CH}_{2} \mathrm{Cl}_{2}$ and $\mathrm{CH}_{3} \mathrm{CN}$, respectively (not shown here). Theoretically, removing an additional methyl group leads to an increase of ionization energy of $\sim 0.4 \mathrm{eV}$ for simple aliphatic amines. ${ }^{46}$ Assuming a similar trend holds in the aromatic system, APP is expected to possess higher ionization energy of $\sim 0.8 \mathrm{eV}$ than DPP, rationalizing its lack of chargetransfer property in the excited state.

The solvent-polarity dependent emission property can be specified more quantitatively according to the theory derived from dielectric polarization, specifying that the spectral shift of the fluorescence upon increasing the solvent polarity depends

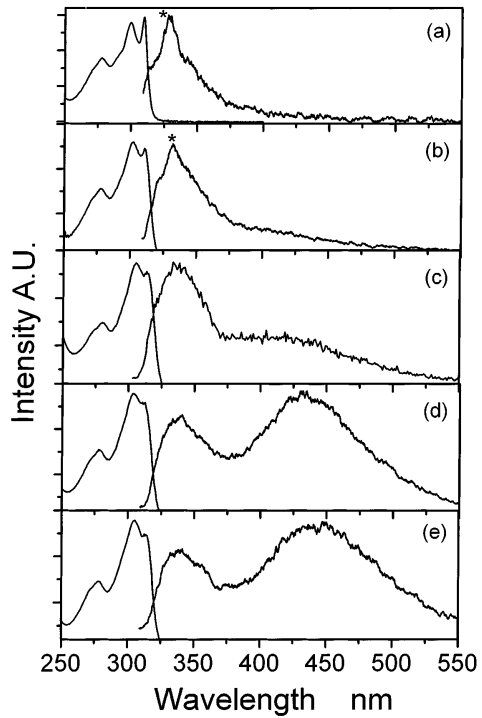

Figure 7. The fluorescence spectra of 1MDPP in various solvents: (a) ethyl ether, (b) ethyl acetate, (c) dichloromethane, (d) acetonitrile, and (e) ethanol. The excitation wavelength is $290 \mathrm{~nm} . *$ denotes the Rayleigh scattering peak.

on the difference in permanent dipole moments between ground and excited states. The magnitude of the excited-state dipole moments can thus be estimated by a method incorporating the fluorescence solvatochromic shift. ${ }^{47-51}$ If the dipole moments of the solute are approximated by a point dipole in the center of a spherical cavity with a radius $a_{0}$, on the basis of nearly solvent independent absorption properties and negligence of the solute polarizability one obtains

$$
\tilde{\nu}_{\mathrm{f}}=\tilde{v}_{\mathrm{f}}^{\mathrm{vac}}-\frac{2\left(\vec{\mu}_{\mathrm{e}}-\vec{\mu}_{\mathrm{g}}\right)^{2}}{h c a_{0}{ }^{3}} \Delta f
$$

where $\tilde{v}_{f}$ and $\tilde{v}_{f}^{\text {vac }}$ in eq $f$ are the spectral position (in terms of 

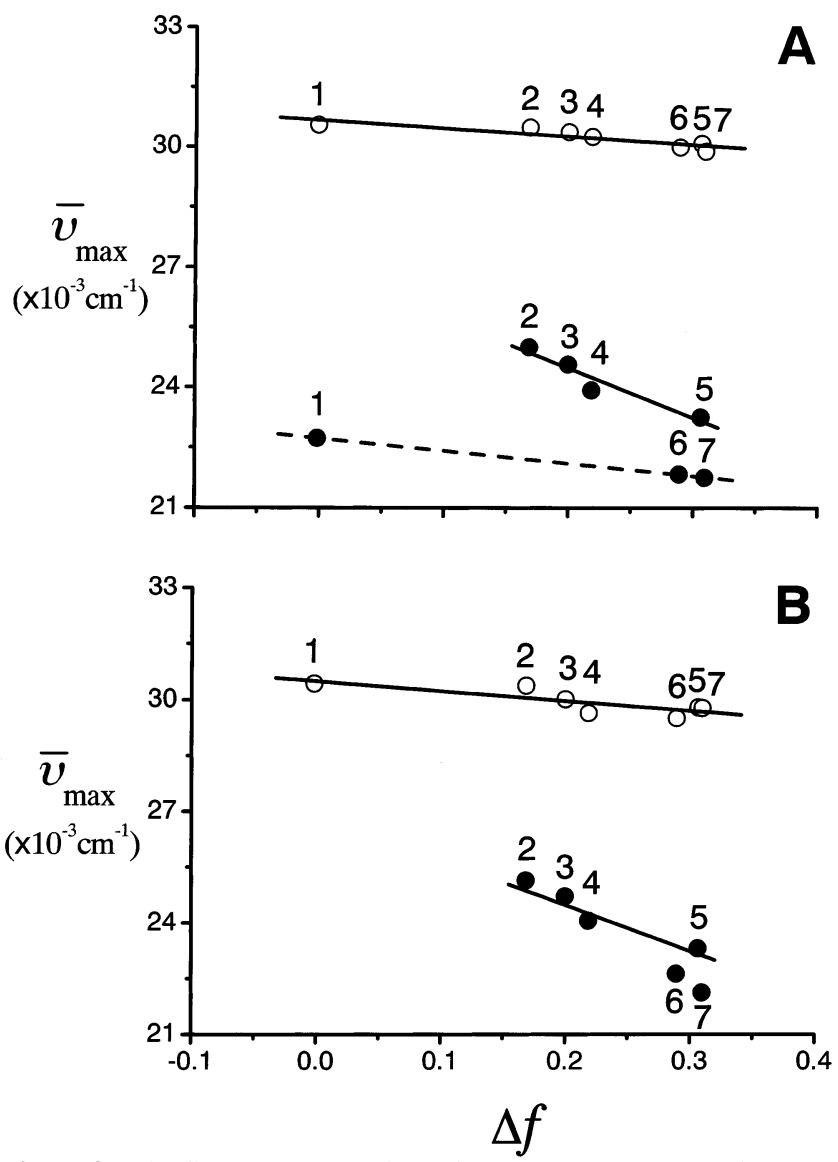

Figure 8. The fluorescence maxima of (A) DPP, (B) 1MDPP (in terms of wavenumber) as a function of $\Delta f$ in various solvents of (1) cyclohexane, (2) ethyl ether, (3) ethyl acetate, (4) dichloromethane, (5) acetonitrile, (6) ethanol, and (7) methanol. (O) The high-frequency band. (-) The low-frequency band.

wavenumber) of the solvation equilibrated fluorescence maxima and the value extrapolated to the diluted gas-phase, respectively, $\vec{\mu}_{\mathrm{g}}$ and $\vec{\mu}_{\mathrm{e}}$ are the dipole moment vectors of the ground and excited states, and $\Delta f$ is the Lippert solvent polarity parameter ${ }^{47}$ which is generally expressed as

$$
\Delta \mathrm{f}=\frac{\epsilon-1}{2 \epsilon+1}-\frac{1}{2} \frac{n^{2}-1}{2 n^{2}+1}
$$

where $\epsilon$ and $n$ denote the static dielectric constant and the refractive index of the solvent, respectively. The plot of spectral maxima for both $\mathrm{F}_{\mathrm{N}}$ and $\mathrm{F}_{\mathrm{C}}$ bands as a function of $\Delta f$ is shown in Figure 8A and B for DPP and 1MDPP, respectively. As predicted by eq $\mathrm{f}$, a linear relationship is found for both $\mathrm{F}_{\mathrm{N}}$ and $\mathrm{F}_{\mathrm{C}}$ bands from ethyl ether to acetonitrile. For DPP the calculated slope of $-1.24 \times 10^{4} \mathrm{~cm}^{-1}$ for the $\mathrm{F}_{\mathrm{C}}$ band is much steeper than that of $-2.02 \times 10^{3} \mathrm{~cm}^{-1}$ for the $\mathrm{F}_{\mathrm{N}}$ band. Similar slopes of $-2.60 \times 10^{3}$ and $-1.3 \times 10^{4} \mathrm{~cm}^{-1}$ were obtained for $\mathrm{F}_{\mathrm{N}}$ and $\mathrm{F}_{\mathrm{C}}$ bands, respectively, in 1MDPP. Apparently, for both DPP and 1MDPP the change of excited-state dipole moment with respect to the ground state is expected to be larger in the $\mathrm{F}_{\mathrm{C}}$ band, consistent with its assignment of the charge-transfer emission. Furthermore, the proton-transfer tautomer emission, i.e., the $\mathrm{F}_{\mathrm{T}}$ band, in cyclohexane can be clearly distinguished from the $\mathrm{F}_{\mathrm{C}}$ band by its far deviation from the Lippert's plot in the aprotic, polar solvents (see Figure 8A), further supporting the different spectral properties between proton-transfer $\left(\mathrm{F}_{\mathrm{T}}\right)$ and charge transfer $\left(\mathrm{F}_{\mathrm{C}}\right)$ emission.

Time-resolved measurements have also been performed for both DPP and 1MDPP in various polar, aprotic solvents, and the results are summarized in Table 1 . Both $F_{N}$ and $F_{C}$ bands show single-exponential decay dynamics with system response limited rise time (i.e. $<15 \mathrm{ps}$ ). The results lead us to conclude that the $\mathrm{F}_{\mathrm{N}}$ band cannot be a precursor for the $\mathrm{F}_{\mathrm{C}}$ band. This in combination with the same excitation spectra for the dual emission indicates that both $\mathrm{F}_{\mathrm{N}}$ and $\mathrm{F}_{\mathrm{C}}$ bands originate from a common Franck-Condon excited state followed by two independent relaxation pathways. More details regarding the quantitative analysis of the excited-state dipole moment as well as relaxation dynamics are elaborated in the discussion section.

3.3. In Protic Solvents (Alcohols). Intriguing excited-state properties were observed in alcohols. In the steady-state measurement, for instance, DPP exhibited dual emission maxima at $335 \mathrm{~nm}\left(\mathrm{~F}_{\mathrm{N}}\right)$ and $460 \mathrm{~nm}$ in ethanol (see Figure 5). While $\tilde{v}_{\max }$ of the $\mathrm{F}_{\mathrm{N}}$ band lies on the linear plot, the correlation for $\tilde{v}_{\max }$ of the long-wavelength band versus $\Delta f$ deviates significantly from the linear behavior of the $\mathrm{F}_{\mathrm{C}}$ band in aprotic solvents (see Figure 8A). The result on one hand may indicate ESICT is operative, while the charge transfer species is subject to the specific hydrogen-bonding interactions with protic solvents. On the other hand, it could reflect different photophysical phenomena other than the charge-transfer event that occurred in the polar, aprotic solvents. Although the former proposed mechanism may be partially supported by a similar dual emission for 1MDPP, where the deviation of the Lippert's plot was also observed for the long wavelength band in ethanol (or methanol, see Figure 8B), some supplementary evidence leads us to discount this proposed mechanism. First, the apparent quantum yield of the long wavelength band $\left(\Phi_{\mathrm{f}} \sim 6.67 \times 10^{-2}\right)$ for DPP in ethanol is higher than that of the $\mathrm{F}_{\mathrm{C}}$ band in the polar, aprotic solvents by $\sim 1$ order of magnitude. In comparison, for 1MDPP, the yield in ethanol is about the same as those of the $\mathrm{F}_{\mathrm{C}}$ band in aprotic solvents (see Table 1). Second, the peak maximum of the long-wavelength emission band for DPP $(460 \mathrm{~nm})$ is red shifted by $\sim 15 \mathrm{~nm}$ from that for 1MDPP in ethanol (445 nm). In comparison, the difference in $\tilde{v}_{\max }$ for the $\mathrm{F}_{\mathrm{C}}$ band is negligible between DPP and 1MDPP in polar, aprotic solvents (see Table 1). It thus seems likely that the large Stokes shifted emission band observed in ethanol for DPP and 1MDPP may exhibit intrinsically different characteristics.

Perhaps the strongest support for the above viewpoint was given by the time-resolved measurement. Drastically different excited-state dynamics were observed between DPP and 1MDPP in ethanol. By monitoring at $>410 \mathrm{~nm}$, a single-exponential decay component with a lifetime of $1.3 \mathrm{~ns}$ was resolved for $1 \mathrm{MDPP}$ in ethanol, while the rise time is beyond the system response of $15 \mathrm{ps}$. In contrast, for DPP the time-dependent fluorescence can be well fitted by two components expressed as

$$
F(t)=a_{1} \mathrm{e}^{-k_{1} t}+a_{2} \mathrm{e}^{-k_{2} t}
$$

Independent of the monitored wavelengths at $>410 \mathrm{~nm}, k_{1}$ and $k_{2}$ were deduced to be $220 \pm 20 \mathrm{ps}^{-1}$ and $3.6 \pm 0.2 \mathrm{~ns}^{-1}$, respectively. However, instead of the positive values for the fitted $a_{2}$ throughout the monitored wavelengths the sign of $a_{1}$ is wavelength dependent. When monitoring at $>450 \mathrm{~nm}$ a negative $a_{1}$ was obtained as indicated by a rise component of $224 \pm 30$ ps (see Figure 9a), which gradually shifts to a positive value, i.e., the appearance of a faster decay component, upon monitoring at shorter emission wavelength (e.g., $410 \mathrm{~nm}$, see Figure $9 b)$. Further analyses revealed that $\left|a_{1} / a_{2}\right|$ was not equal to 1.0 and was found to be wavelength dependent. When the timedependent fluorescence was monitored at the steady-state emission maximum of $\sim 460 \mathrm{~nm}$ this value is deduced to be 


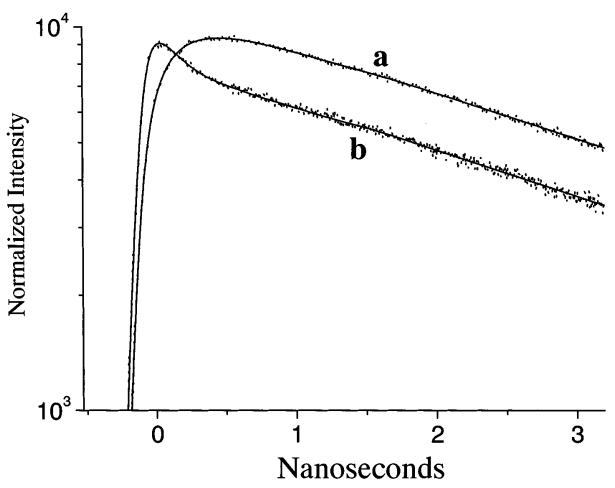

Figure 9. The logarithm plot of the time-dependent fluorescence of DPP in ethanol and its corresponding best-fitted curve. The emission wavelength was monitored at (a) $465 \mathrm{~nm}$ and (b) $410 \mathrm{~nm}$. $\lambda_{\mathrm{ex}}=266$ nm.

$\sim 0.5$, indicating that $\sim 50 \%$ of the fluorescence promptly exists, while the remaining $50 \%$ has not yet been populated. The results confirm the existence of two species at $>410 \mathrm{~nm}$. Due to its negligible emission intensity at $>410 \mathrm{~nm}$, the possibility of the observed decay dynamics originating, in part, from the residue of the normal emission (i.e., the $\mathrm{F}_{\mathrm{N}}$ band, $\lambda_{\max } \sim 335 \mathrm{~nm}$ ) can be excluded. DPP possesses a similar parent structure to 7AI where the pyridinic nitrogen and pyrrolic hydrogen provide proton donating and accepting sites, respectively. In the previous section (3.1), DPP has been shown to undergo ESDPT in its dimer and complexed form with acetic acid in cyclohexane. Knowing that 7AI also undergoes alcohol catalyzed proton transfer in the excited state, ${ }^{21-25,26 a}$ it is thus reasonable to propose the occurrence of ESDPT for DPP in ethanol, resulting in a proton-transfer tautomer emission (denoted by the $\mathrm{F}_{\mathrm{T}}$ band). Evidence to support this viewpoint is given by 7MDPP, a proton-transfer analogue of DPP, which exhibits a normal Stokes shifted fluorescence with spectral and dynamic features $\left(\lambda_{\max }\right.$ $\sim 460 \mathrm{~nm}, \tau_{\mathrm{f}} \sim 3.4 \mathrm{~ns}$, and $\Phi_{\mathrm{f}} \sim 8.7 \times 10^{-2}$ ) similar to that of the long-wavelength band of DPP in ethanol. Furthermore, an interesting comparison can be made by plotting $\tilde{\nu}_{\max }$ versus $\Delta f$ for the $\mathrm{F}_{\mathrm{T}}$ band of DPP in cyclohexane (i.e. the dimeric form), ethanol and methanol, giving rise to a sufficiently linear correlation (see Figure 8A, dashed line), supporting their similar spectral properties.

As shown in Table 1, the lifetime of normal emission (i.e. the $\mathrm{F}_{\mathrm{N}}$ band) was $\sim 50 \mathrm{ps}$ in ethanol, while the rise time of the proton-transfer tautomer emission was well resolved to be 220 ps. It is thus very unlikely that the precursor of ESDPT originates from the normal form of DPP (i.e. the species attributed to the $\mathrm{F}_{\mathrm{N}}$ emission), but more plausibly through its charge transfer species. Consequently, a mechanism incorporating charge/proton-transfer coupled reaction was tentatively proposed in Scheme 1c. Upon Franck Condon excitation, the charge-transfer reaction takes place, accompanied by fast solvent relaxation dynamics, to reach a stabilized charge-transfer state. The equilibrated charge-transfer state further undergoes solvent (ethanol) assisted, irreversible ESDPT, resulting in a protontransfer tautomer emission. The rise kinetics of the tautomer emission depend on the types of short-carbon chain monoalcohols used, being 170, 220, and $250 \mathrm{ps}^{-1}$ in methanol, ethanol, and propanol, respectively. In addition, a deuterium isotope effect was observed in the rise dynamics. For example, $k_{\mathrm{pt}}{ }^{\mathrm{D}}$ was measured to be $\sim 648 \mathrm{ps}^{-1}$ in ethanol- $d$, giving $k_{\mathrm{pt}} \mathrm{H} / k_{\mathrm{pt}}^{\mathrm{D}}$ to be 2.9. It is thus believed that the mechanism of alcohol catalyzed ESDPT in DPP should be similar to a two-step mechanism proposed for 7AI and its corresponding analogues, ${ }^{29,34}$ incorporating equilibrium solvation followed by a rapid proton transfer, which is possibly governed by a tunneling mechanism shown in Scheme 1c. For this case $k_{\mathrm{pt}}$ can be further expressed by

$$
k_{\mathrm{pt}}=\frac{k_{1}}{k_{-1}} k_{\mathrm{pt}}^{0}=k_{\mathrm{pt}}{ }^{0} e^{-\Delta G / R T}
$$

where $k_{\mathrm{pt}}{ }^{0}$ and $\Delta G$, respectively, denote the proton tunneling rate and difference in free energy between cyclic and neighbor-

SCHEME 1: The Proposed Photophysics of DPP in (a) Nonpolar Solvents (e.g., Cyclohexane); (b) Polar, Aprotic Solvents (e.g., Acetonitrile); and (c) Protic Solvents (e.g., Ethanol).<smiles>CNc1nccc([N+](=O)[O-])c1N</smiles>

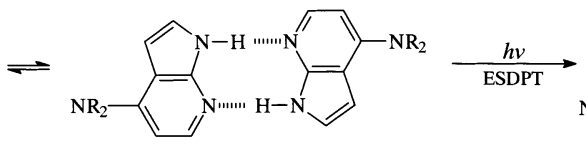

in nonpolar solvents (a)

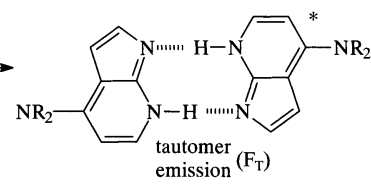<smiles>N#[Y16]c1ccnc2[nH]ccc12</smiles>

in polar, aprotic solvents (b)

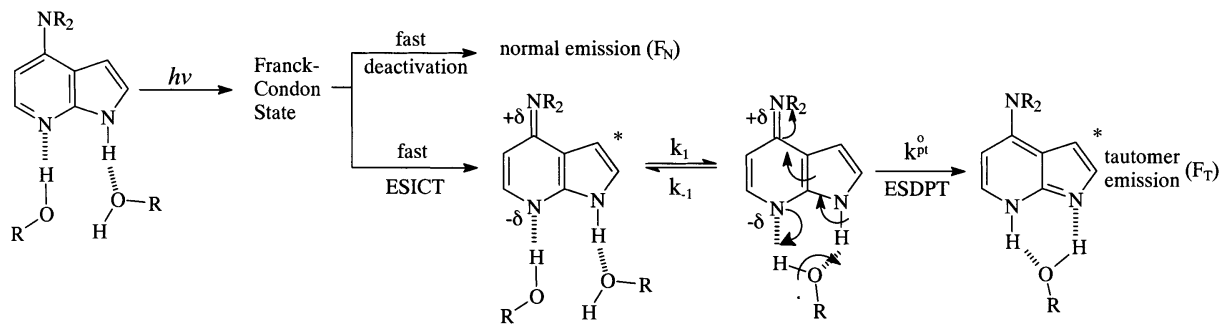

in protic solvents (c) 


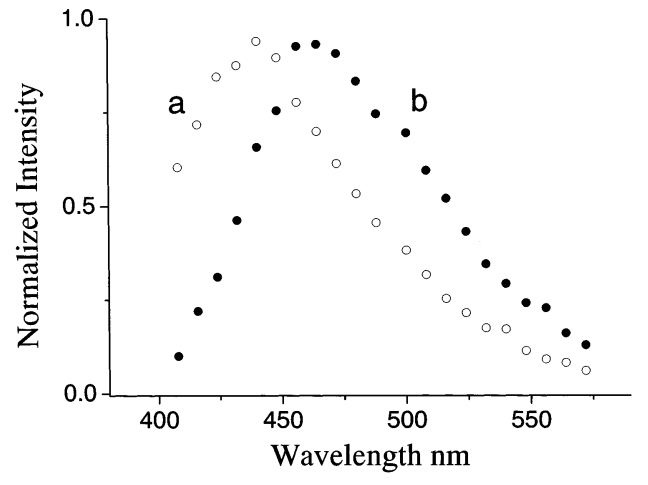

Figure 10. The time-dependent spectral evolution of DPP in ethanol acquired at (a) (O) $0-150 \mathrm{ps,} \mathrm{(b)} \mathrm{( \bullet )>1.0} \mathrm{ns.} \lambda_{\mathrm{ex}}=266 \mathrm{~nm}$.

bonded structures. ${ }^{29} \mathrm{~A}$ distinct difference in mechanism between DPP and 7AI is that the precursor of the ESDPT in DPP is a charge-transfer species, while the normal (neutral) species is operative in the case of 7AI.

On the basis of the prompt population $(<15 \mathrm{ps})$ of the chargetransfer species followed by ESDPT, the time-dependent signal for $F_{\mathrm{C}}(t)$ (charge-transfer emission) and $F_{\mathrm{T}}(t)$ (proton-transfer emission) in ethanol can be expressed as

$$
\begin{gathered}
F_{\mathrm{C}}(t)=\alpha k_{\mathrm{r}}^{\mathrm{C}}(\tilde{v})\left[F_{\mathrm{C}}\right]_{0} \mathrm{e}^{-\left(k_{\mathrm{C}}+k_{\mathrm{p} t}\right) t} \\
F_{\mathrm{T}}(t)=\frac{\alpha k_{\mathrm{r}}^{\mathrm{T}}(\tilde{v}) k_{\mathrm{pt}}\left[F_{\mathrm{C}}\right]_{0}}{k_{\mathrm{T}}-k_{\mathrm{C}}-k_{\mathrm{pt}}}\left[\mathrm{e}^{-\left(k_{\mathrm{C}}+k_{\mathrm{pt}}\right) t}-\mathrm{e}^{-k_{\mathrm{T}} t}\right]
\end{gathered}
$$

where $\alpha$ denotes the instrument factor, including sensitivity, alignment, etc., of the detecting system, $\left[F_{\mathrm{C}}\right]_{0}$ is the initial population of the charge-transfer species in the excited state, and $k_{\mathrm{r}} \mathrm{C}(\tilde{v})$ and $k_{\mathrm{r}}^{\mathrm{T}}(\tilde{v})$ are radiative decay rates of charge-transfer and proton-transfer tautomer emission, respectively. $k_{\mathrm{C}}$ is the decay rate of the $F_{\mathrm{C}}$ band excluding the rate of proton-transfer reaction, and $k_{\mathrm{T}}$ denotes the observed decay rate of the tautomer emission. It is reasonable to assume $k_{\mathrm{pt}}$ to be $\gg k_{\mathrm{C}}+k_{\mathrm{T}}$ in protic solvents. As a result, the sum of $F_{\mathrm{C}}(t)$ and $F_{\mathrm{T}}(t)$ at a monitored specific wavelength (e.g. $>400 \mathrm{~nm}$ ) can be expressed as

$$
\begin{aligned}
& F_{\mathrm{C}}(t)+F_{\mathrm{T}}(t)= \\
& \alpha\left[F_{\mathrm{C}}\right]_{0}\left[\left(k_{\mathrm{r}}^{\mathrm{C}}(\tilde{v})-k_{\mathrm{r}}^{\mathrm{T}}(\tilde{v})\right) \mathrm{e}^{-k_{\mathrm{p} t} t}+k_{\mathrm{r}}^{\mathrm{T}}(\tilde{v}) \mathrm{e}^{-k_{\mathrm{T}} t}\right]= \\
& a_{1} \mathrm{e}^{-k_{\mathrm{p} t} t}+a_{2} \mathrm{e}^{-k_{\mathrm{T}} t}
\end{aligned}
$$

Since $k_{\mathrm{r}}^{\mathrm{C}}(\tilde{v})$ and $k_{\mathrm{r}}^{\mathrm{T}}(\tilde{v})$ incorporate the Franck-Condon factor, $k_{\mathrm{r}}^{\mathrm{C}}(\tilde{v})-k_{\mathrm{r}}^{\mathrm{T}}(\tilde{v})$ is expected to be wavelength dependent, rationalizing the variation of preexponential factor $a_{1}$ in both value and sign.

As predicted from the $\mathrm{F}_{\mathrm{C}}$ band of 1MDPP (see Figure 7), the charge-transfer emission is expected to exhibit a peak maximum at $\sim 445 \mathrm{~nm}$ in ethanol. In the steady-state measurement, although the fluorescence yield of the charge-transfer emission is obscured in ethanol due to the dominant rate of ESDPT in DPP, an attempt has been made to resolve the individual $\mathrm{F}_{\mathrm{C}}$ and $\mathrm{F}_{\mathrm{T}}$ bands by the time-dependent spectralevolution technique. Figure 10a shows the emission spectrum obtained by integrating the photon-counting signal in a time delay interval of $0-150 \mathrm{ps}$. It is apparent that the resulting spectrum which has a maximum at $\sim 440 \mathrm{~nm}$ is blue shifted versus that of $\sim 460 \mathrm{~nm}$ obtained at a time delay of $>1.0 \mathrm{~ns}$ (see Figure 10b). The time-resolved spectral evolution substantiates our proposal of two emitting species in the long wavelength
TABLE 2: The Magnitude (Unit: Debye) and Angle (Unit: Degree) of Dipole Moment for DPP Calculated by Various Theoretical Approaches

\begin{tabular}{lcr}
\hline \multicolumn{1}{c}{ method $^{a}$} & magnitude & angle \\
\hline & Ground State & \\
MP2/6-31G(d, p) & 3.0147 & $164.65^{b}$ \\
HF/6-31G(d,p) & 4.0238 & 164.16 \\
AM1 & 2.727 & 159.80 \\
PM3 & 2.595 & 157.76 \\
INDO/S-CI & 1.688 & 143.13 \\
& Excited State $\left(\Phi=0^{\circ}\right)$ & \\
& $6.1^{d}$ & $28.0^{c}$ \\
& Excited State $\left(\Phi=90^{\circ}\right)$ & \\
& $13.2^{d}$ & $36.7^{c}$
\end{tabular}

${ }^{a}$ The angle is specified as the orientation of dipole moment vector relative to the $\mathrm{C}_{8}-\mathrm{C}_{9}$ bond (see Figure 1) counted positive clockwise. ${ }^{b}$ All semiempirical calculations were performed by HyperChem 6.03 on Win 2000 professional at Intel PIII 733 computer. ${ }^{c}$ The angle is specified as the orientation of dipole moment vector relative to the ground state (i.e., structure N, see Figure 1) using INDO/S-CI method. ${ }^{d}$ Values were obtained by the best fit of Figure $8 \mathrm{~A}$ in polar, aprotic solvents using eq $\mathbf{f}$ where magnitude of dipole moment in the ground state and angles between ground and excited states were calculated by MP2/6-31(d, p) and INDO/S-CI methods, respectively (see text).

band, ascribed to the charge-transfer precursor and its subsequent proton-transfer tautomer emission.

\section{Discussion}

4.1. Excited-State Charge-Transfer Properties. Much of the evidence presented in previous sections has ambiguously drawn the conclusion that the excited-state charge transfer reaction is operative for DPP in polar solvents. In this section, we have made an attempt to further explore the excited-state charge transfer properties in DPP. One key issue is to see if the ESICT mechanism incorporates the lock of a charge separation through the rotation of the dimethyl amino group, namely the twist intramolecular charge transfer (TICT). ${ }^{52-55}$ However, excited-state proton transfer is prohibited in $N,{ }^{6} N^{6}$-dimethyladenosine since the pyrrolic nitrogen has been attached to a sugar moiety. Experimentally, a direct verification of such a proposed mechanism may require the design of a rigid alkyl amino substituent so that the rotation is sterically hindered with respect to the parent 7AI, prohibiting the TICT dynamics. Unfortunately such a synthetic goal has not yet been achieved in our laboratory at this stage. Alternatively, the possibility of a TICT mechanism operated in DPP was herein examined by theoretical approaches.

According to the ab initio approach (MP2/6-31G(d, p)) the geometry optimized structure of DPP in the ground state revealed two carbon atoms in the dimethylamino group lying on the same symmetry plane with respect to the parent 7AI moiety ( $\Phi \sim 0^{\circ}$, structure $\mathbf{N}$ in Figure 1). Conversely, a DPP structure with the dimethyl group being perpendicular to the plane of 7AI moiety $\left(\Phi \sim 90^{\circ}\right.$, structure $\left.\mathbf{C}\right)$ is calculated to be higher in energy than that of the in-plane one by $4.5 \mathrm{kcal} / \mathrm{mol}$. The difference is more or less the same upon incorporating semiempirical PM3-SMx solvation models ${ }^{57}$ to obtain the solvation free energy in various aprotic solvents, which is then added to the calculated "gas phase" energies. Thus, structure $\mathbf{N}$ was concluded to be the most stable conformer in the ground state, of which the magnitude of dipole moment is deduced to be $3.01 \mathrm{D}$ with its orientation $165^{\circ}$ in plane relative to the $\mathrm{C}_{8}-$ $\mathrm{C}_{9}$ bond counted positive counterclockwise. The vector of dipole moment was also calculated by various computation methods including AM1, PM3, and Hartree-Fock methods incorporating different basis sets. The results listed in Table 2 indicate that 


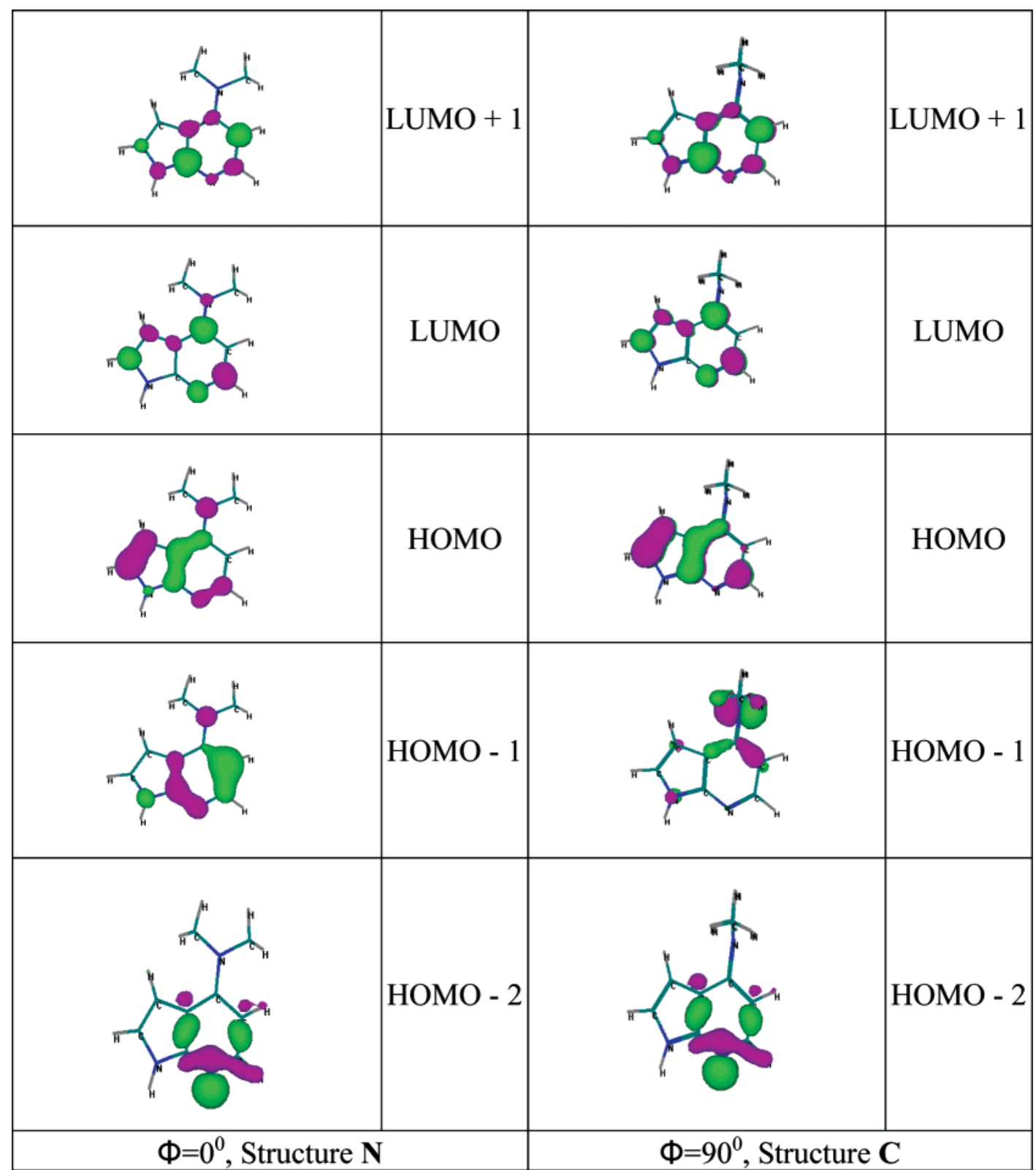

Figure 11. The electron-density distribution of the two lowest unoccupied and three highest occupied frontier molecular orbitals calculated (INDO/ S-CI) for DPP in the planar $\left(\Phi=0^{\circ}\right)$ and perpendicular $\left(\Phi=90^{\circ}\right)$ conformations.

depending on the method applied, the magnitudes of the calculated dipole moment diversify, whereas the orientation of dipole moment is less affected.

Based on the results of INDO/S-CI calculation (see Experimental Section), Figure 11 depicts the two lowest unoccupied and three highest occupied frontier molecular orbitals calculated for DPP in the planar $\left(\Phi=0^{\circ}\right)$ and twisted $\left(\Phi=90^{\circ}\right)$ conformations, where $\Phi$ specifies the rotational angle of $\mathrm{N}\left(\mathrm{CH}_{3}\right)_{2}$ relative to the parent 7AI plane. Except for the second highest occupied orbital (HOMO-1) all rest frontier molecular orbitals possess the same configuration between $\mathbf{N}$ and $\mathbf{C}$ conformers. The $\pi$-symmetry configuration was found for LUMO+1, LUMO and HOMO orbitals, while HOMO-2 is mainly attributed to the lone pair orbital of the pyridinic nitrogen. Instead of the $\pi$-symmetry for the HOMO-1 orbital in $\mathbf{N}$ conformer, the HOMO-1 orbital in structure $\mathbf{C}$ possesses a $\sigma$-symmetry where the charge density is largely localized on the dimethylamino nitrogen. The lowest Franck-Condon singlet excitation in the planar form was dominated by $\mathrm{HOMO} \rightarrow$ LUMO+1 and HOMO-1 $\rightarrow$ LUMO (32 $\left.206 \mathrm{~cm}^{-1}\right)$ transition
TABLE 3: The Lowest Singlet Electronic Transitions Calculated for DPP in the Planar $\left(\Phi=0^{\circ}\right)$ and Twisted $(\Phi$ $=90^{\circ}$ ) Conformations Using the INDO/S-CI Method (See Experimental Section for the Detailed Description)

\begin{tabular}{lcll}
\hline \multicolumn{1}{c}{ transition } & $\begin{array}{c}\tilde{v} \\
\left(\mathrm{~cm}^{-1}\right)\end{array}$ & \multicolumn{1}{c}{$f^{\text {a }}$} & dominant configurations ${ }^{b}$ \\
\hline & & $\Phi=0^{\circ}$ & \\
$\mathrm{S}_{0} \rightarrow \mathrm{S}_{1}\left(\pi \pi^{*}\right)$ & 32206 & 0.038 & $\mathrm{H} \rightarrow \mathrm{L}+1, \mathrm{H}-1 \rightarrow \mathrm{L}$ \\
$\mathrm{S}_{0} \rightarrow \mathrm{S}_{2}\left(\mathrm{n} \pi^{*}\right)$ & 33772 & 0 & $\mathrm{H}-2 \rightarrow \mathrm{L}$ \\
$\mathrm{S}_{0} \rightarrow \mathrm{S}_{3}\left(\pi \pi^{*}\right)$ & 34916 & 0.3177 & $\mathrm{H} \rightarrow \mathrm{L}$ \\
& & $\Phi=90^{\circ}$ & \\
& & \\
$\mathrm{S}_{0} \rightarrow \mathrm{S}_{1}\left(\sigma \pi^{*}\right)$ & 27030 & 0.001 & $\mathrm{H}-1 \rightarrow \mathrm{L}$ \\
$\mathrm{S}_{0} \rightarrow \mathrm{S}_{2}\left(\pi \pi^{*}\right)$ & 32258 & 0.086 & $\mathrm{H} \rightarrow \mathrm{L}, \mathrm{H} \rightarrow \mathrm{L}+1$ \\
$\mathrm{~S}_{0} \rightarrow \mathrm{S}_{3}\left(\mathrm{n} \pi^{*}\right)$ & 32680 & 0 & $\mathrm{H}-2 \rightarrow \mathrm{L}$
\end{tabular}

${ }^{a}$ Oscillator strength. ${ }^{b} \mathrm{H}$ : HOMO. L: LUMO.

possessing a ${ }^{1} \pi \pi^{*}$ configuration (see Table 3 ). In contrast, it was altered to HOMO-1 ( $\sigma$-symmetry) $\rightarrow$ LUMO $(\pi$-symmetry) in the case of the $\mathbf{C}$ conformer $\left(\sim 27030 \mathrm{~cm}^{-1}\right)$, indicating that the lowest excited singlet state for structure $\mathbf{C}$, to a certain extent, possesses a charge transfer character where the electron 
density flows from dimethylamino substituent to the ring, particularly the pyridinic nitrogen. In summary, theoretical approaches for both ground and lowest-lying excited states of DPP are qualitatively in accordance with a TICT model originally proposed by Grabowski and co-workers. ${ }^{52}$ The calculated charge-transfer emission of $27030 \mathrm{~cm}^{-1}$ in a vacuum is consistent with the extrapolation of $\tilde{v}_{\max }$ for the $\mathrm{F}_{\mathrm{C}}$ band to $\Delta f=0$ (Figure 8A), which gives rise to an intercept of 26950 $\mathrm{cm}^{-1}$ for DPP in the gas phase. Further solvent relaxation must take place to stabilize the point dipole of the charge-transfer species, resulting in a larger Stokes shifted emission upon increasing the solvent polarity. It should also be noted that analyses have not been performed in consideration of various twisting angles. Thus, the possibility of TICT taking place at a certain small but critical angle rather than the $\Phi=90^{\circ}$ conformer cannot be ruled out at this stage. Further studies on the molecular design of an intrinsically twisted DPP analogue are crucial to resolve this issue.

The excited-state dipole moments for the solvated DPP structures attributed to either $\mathrm{F}_{\mathrm{N}}$ or $\mathrm{F}_{\mathrm{C}}$ bands could be estimated from the slopes depicted in Figure 8. Because the ground state dipole moment for DPP has not yet been determined experimentally, we adopted the value of $3.01 \mathrm{D}$ deduced from the MP2/6-31G $(d, p)$ method incorporating the electron correlation. As mentioned in the previous section, the orientation of the dipole moment is much more reliable than its magnitude, especially in the excited state, among various computational methods. On the basis of the INDO/S-CI method, the angles of dipole moment between ground (structure $\mathbf{N}$ ) and $\mathrm{F}_{\mathrm{N}}$ (the first ${ }^{1} \pi \pi^{*}$ state of structure $\mathbf{N}$ ) or $\mathrm{F}_{\mathrm{C}}$ (the first ${ }^{1} \sigma \pi^{*}$ state of structure C) state were estimated to be $28.0^{\circ}$ and $36.7^{\circ}$, respectively (see Table 2). If charge transfer from the dimethylamino group to the pyridinic nitrogen makes a key contribution, we would expect a short-axis $\left(\mathrm{C}_{8}-\mathrm{C}_{9}\right)$-oriented excited-state dipole moment of the $\mathbf{C}$ state. This viewpoint is supported by the nearly parallel orientation $\left(\sim 180^{\circ}\right)$ of $\vec{\mu}_{\mathrm{C}^{*}}$ relative to the $\mathrm{C}_{8}-\mathrm{C}_{9}$ bond (see INDO/S-CI method in Table 2). Employing these calculated angles as fixed parameters, magnitudes of excited-state dipole moment for both $\mathrm{F}_{\mathrm{N}}$ and $\mathrm{F}_{\mathrm{C}}$ states can thus be estimated. In eq f, the radius of spherical cavity $a_{\text {o }}$ was calculated to be $4.57 \AA$ based on a geometry optimized structure of DPP (HF/6-31G(d, p)). Accordingly, a best fit of Figure 8 using eq $\mathrm{f}$ gives the magnitude of dipole moment to be 6.1 and $13.2 \mathrm{D}$ for $\mathbf{N}^{*}$ and C $^{*}$, respectively (see Table 2 ). The combination of experimental and theoretical approaches predicts a relative trend of $\left|\mu_{\mathrm{C}^{*}}\right|>$ $\left|\mu_{\mathrm{N}^{*}}\right|>\left|\mu_{\mathrm{g}}\right|$ for DPP. A larger solvatochromic shift is then expected for the charge-transfer state (i.e., the $\mathbf{C}^{*}$ state) in comparison to the normal state $\left(\mathbf{N}^{*}\right)$, rationalizing the difference in solvent-polarity dependence of $\mathrm{F}_{\mathrm{N}}$ and $\mathrm{F}_{\mathrm{C}}$ emissions (i.e., the $\tilde{v}_{\max }$ value in Figure 8).

4.2. Relaxation Dynamics in Aprotic Solvents. The timeresolved fluorescence studies reveal that the rise time of the $\mathrm{F}_{\mathrm{C}}$ emission band is irresolvable (i.e. $<15 \mathrm{ps}$ ), while a finite lifetime of 30-160 ps was resolved for the $F_{N}$ band in various solvents studied. Careful analyses also conclude that preexponential factors of the fitted decay dynamics for both $\mathrm{F}_{\mathrm{N}}$ and $\mathrm{F}_{\mathrm{C}}$ bands are positive throughout the spectral region of 300-600 $\mathrm{nm}$. No negative preexponential values can be resolved in our current time correlated photon-counting measurement. This in combination with identical excitation spectra suggests that $\mathrm{F}_{\mathrm{N}}$ and $\mathrm{F}_{\mathrm{C}}$ states share a common Franck-Condon state. Upon excitation, this initially prepared electronic state rapidly relaxes to $\mathrm{F}_{\mathrm{N}}$ and $\mathrm{F}_{\mathrm{C}}$ states which become decoupled without intercon-

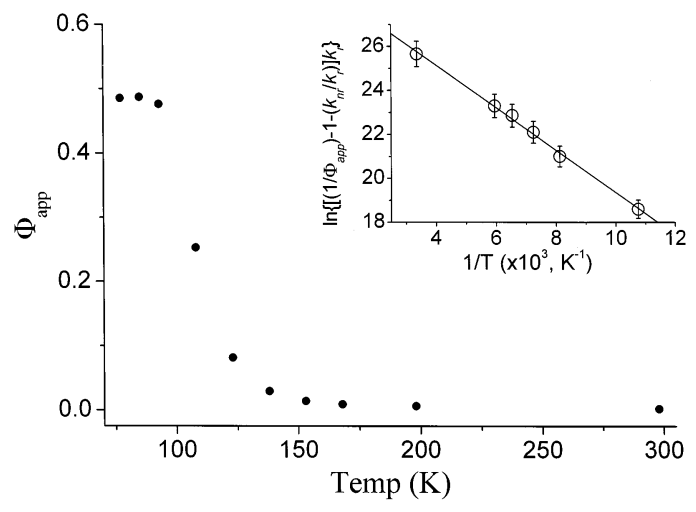

Figure 12. The plot of apparent quantum yield $\left(\Phi_{\text {app }}\right)$ for the $F_{N}$ band of DPP as a function of the temperature (T). Insert: The plot $\ln \{(1 /$ $\left.\Phi_{\text {app }}-1-k_{\mathrm{nr}} / k_{\mathrm{r}}\right) k_{\mathrm{r}}$ \} versus $1 / T$ from 298 to $80 \mathrm{~K}$ and a best linear least-squares fitting curve using eq i.

version. Consequently, these two states decay independently, and the $\mathrm{F}_{\mathrm{N}}$ state cannot be the precursor of the $\mathrm{F}_{\mathrm{C}}$ state.

A strong support for this model was given by the temperaturedependent fluorescence spectra of DPP in 2MTHF shown in Figure 12. The $\mathrm{F}_{\mathrm{N}}$ emission revealed strong temperature dependence. Its apparent quantum yield $\Phi_{\text {app }}$ increased from $1.8 \times 10^{-3}$ at $298 \mathrm{~K}$ to a plateau $\left(\Phi_{\text {app }} \sim 0.47\right)$ at $\sim 90 \mathrm{~K}$ and remained constant at lower temperatures. There is a sharp increase of the $\mathrm{F}_{\mathrm{N}}$ intensity in the range between 150 and 100 $\mathrm{K}$ where a turning point at $\sim 115 \mathrm{~K}$ was observed. In contrast, the intensity of the $\mathrm{F}_{\mathrm{C}}$ band was nearly temperature independent, and only increased by $\sim 1.5$-fold from 298 down to $80 \mathrm{~K}$ (not shown here). The steady-state results were further compared with the temperature-dependent relaxation dynamics. The lifetime monitored at the $F_{N}$ band (e.g., $340 \mathrm{~nm}$ ) follows the steady-state pattern where it increased significantly from 70 ps at $298 \mathrm{~K}$ to $3.2 \mathrm{~ns}$ at $80 \mathrm{~K}$. Conversely, the $\mathrm{F}_{\mathrm{C}}$ band increased only slightly from 1.5 to $2.1 \mathrm{~ns}$. Under a system response limit of $15 \mathrm{ps}$, rise dynamics cannot be extracted for either the $\mathrm{F}_{\mathrm{N}}$ or $\mathrm{F}_{\mathrm{C}}$ band throughout the temperature-dependent study, further indicating that at the studied temperatures, the $\mathrm{F}_{\mathrm{N}}$ species cannot be the precursor of the $\mathrm{F}_{\mathrm{C}}$ band. Assuming a temperatureindependent radiative decay rate $k_{\mathrm{r}}$ for the $\mathrm{F}_{\mathrm{N}}$ band, the observed temperature-dependent decay rate $k_{\mathrm{obs}}$ can be expressed as $k_{\mathrm{obs}}$ $=k_{\mathrm{r}}+k_{\mathrm{nr}}+k_{\mathrm{nr}}(T)$. Accordingly, the apparent quantum yield is deduced to

$$
\Phi_{\mathrm{app}}=\frac{k_{\mathrm{r}}}{k_{\mathrm{r}}+k_{\mathrm{nr}}+k_{\mathrm{nr}}(T)}
$$

where $k_{\mathrm{nr}}$ denotes the temperature independent radiationless decay rate constant, possibly involving internal conversion, intersystem crossing, etc. The temperature-dependent radiationless decay rate constant $k_{\mathrm{nr}}(T)$ can be further expressed as an Arrhenius type of thermally deactivated pathway of $k_{\mathrm{nr}}(T)=$ $A \mathrm{e}^{-E_{\mathrm{a}} / R T}$, which is then plugged into eq $\mathrm{h}$ to obtain

$$
\ln \left\{\left(\frac{1}{\Phi_{\mathrm{app}}}-1-\frac{k_{\mathrm{nr}}}{k_{\mathrm{r}}}\right) k_{\mathrm{r}}\right\}=\ln A-\frac{E_{\mathrm{a}}}{R T}
$$

As indicated by steady-state and time-resolved measurements, the lifetime and intensity of the $\mathrm{F}_{\mathrm{N}}$ band at $<90 \mathrm{~K}$ are nearly temperature independent. Thus, $k_{\mathrm{nr}}(T)$ is assumed to be negligible, and $\Phi_{\text {app }}$ expressed in eq h can be simplified to $k_{\mathrm{r}} /\left(k_{\mathrm{nr}}+\right.$ $k_{\mathrm{r}}$ ), which was measured to be $\sim 0.47$ at $80 \mathrm{~K}$. On the other hand, $k_{\mathrm{obs}}$ was resolved to be $3.1 \times 10^{8} \mathrm{~s}^{-1}$ at $80 \mathrm{~K}$. Accordingly $k_{\mathrm{r}}$ and $k_{\mathrm{nr}}$ were deduced to $1.5 \times 10^{8}$ and $1.6 \times 10^{8} \mathrm{~s}^{-1}$, 
respectively. With all parameters provided, the plot of $\ln \{(1 /$ $\left.\left.\Phi_{\text {app }}-1-k_{\mathrm{nr}} / k_{\mathrm{r}}\right) k_{\mathrm{r}}\right\}$ as a function of reciprocal of the temperature reveals a straight line and $E_{\mathrm{a}}$ was deduced to be $2.1 \mathrm{kcal} / \mathrm{mol}$ with a frequency factor $A$ of $3.6 \times 10^{12} \mathrm{~s}^{-1}$ (see insert of Figure 12).

The fast depopulation of the $\mathrm{F}_{\mathrm{N}}$ state may be tentatively rationalized by the proximity of the $n \pi^{*}$ state which has been calculated to be in the second excited state and was estimated to be only $\sim 4.4 \mathrm{kcal} / \mathrm{mol}$ above the lowest singlet $\pi \pi^{*}$ state (see Table 3). Note this value is on the same magnitude as the activation energy (i.e., $2.1 \mathrm{kcal} / \mathrm{mol}$ ) of the temperaturedependent radiationless pathway for DPP in 2MTHF. As a result, the Franck-Condon excited state may undergo a fast thermally activated ${ }^{1} \pi \pi^{*} \rightarrow{ }^{1} \mathrm{n} \pi^{*}$ internal conversion. The vibronic mixing between $n \pi^{*}$ and $\pi \pi^{*}$ states may explain the extremely low fluorescence yield of the $\mathrm{F}_{\mathrm{N}}$ state. In an extreme case, the corresponding pseudo Jahn-Teller distortion may be incorporated, enhancing a nonradiative decay channel. Such a mechanism requires the molecule to be distorted along a nontotally symmetric (i.e., out-of-plane) coordinate. ${ }^{58-60}$ Twisting the exocyclic dimethylamino group possibly induces a nontotally symmetric distortion. Accordingly, the relationship between movement into the charge-transfer state and nonradiative decay of the $F_{N}$ state might be considered an efficient deactivation pathway. This proposed mechanism, however, is discounted via studying the spectral properties of APP. Although ESICT is prohibited in APP due to the high ionization energy of the amino substituent, the florescence (i.e., the $\mathrm{F}_{\mathrm{N}}$ band) yield is still low $\left(\sim 10^{-3}\right)$ in all polar solvents studied, indicating that radiationless pathways other than the charge-transfer reaction dominate the decay dynamics of the $\mathrm{F}_{\mathrm{N}}$ band.

\section{Conclusions}

In summary, we have reported dual photophysical properties, i.e., the excited-state proton transfer versus charge-transfer reactions, on DPP in different environments. To summarize the viewpoints made in previous sections, Scheme $1 \mathrm{a}-\mathrm{c}$ depicts the photophysical pathways of DPP categorized by nonpolar, polar, aprotic, and protic solvents. Several remarks can be pointed out on the basis of Scheme 1: (1) The electron donating property of the dimethylamino group on DPP enhances the dual hydrogen bonding strength in both DPP dimer and DPP/acetic acid complex, which upon excitation undergo ultrafast double proton transfer $\left(k_{\mathrm{pt}}>6.7 \times 10^{10} \mathrm{~s}^{-1}\right)$, resulting in an iminelike tautomer emission in nonpolar solvents. (2) The excitedstate intramolecular charge transfer takes place in polar, aprotic solvents, of which the relaxation dynamics are independent of the normal emission (i.e., the $\mathrm{F}_{\mathrm{N}}$ band). As supported by the theoretical approach, the mechanism incorporating TICT may be operative, resulting in a large change of the dipole moment. (3) In protic solvents such as in ethanol, following the fast excited-state intramolecular charge transfer and solvent relaxation, the solvent catalyzed proton-transfer reaction takes place (e.g., $\sim 220 \mathrm{ps}^{-1}$ in ethanol), resulting in an imine-like tautomer emission. Thus, DPP provides an ideal model to study the dual excitation behavior of proton transfer vs charge transfer, which is unique among the 7AI analogues.

Although the spectroscopy and dynamics have been studied comprehensively, several perplexities remain unsolved. The main question lies in relation to the branching ratio as well as the corresponding dynamics for the population of the $F_{N}$ and $F_{C}$ species. While TICT seems to be operative in the case of DPP, definitive proof and correlation with the twisting angles remain to be explored. It should be noted that to explain the spectroscopy and dynamics of dual emission for $N,{ }^{6} N^{6}$-di- methyladenosines, Albinsson and co-workers ${ }^{56}$ have proposed a similar nonprecursor-sater type of TICT mechanism. In contrast, Andreas et al. ${ }^{61}$ recently claimed a precursor-sater relation for the dual emission of $N,{ }^{6} N^{6}$-dimethyladenine derivatives. For the case of DPP, the independent relaxation dynamics between $F_{N}$ and $F_{C}$ bands leads us to tentatively adopt the nonprecursor-sater TICT mechanism at this stage. Focus on design and synthesis of DPP derivatives so that the electrondonating site can be geometrically locked to test the proposed TICT/ESDPT coupled mechanism is currently in progress. It is believed that this approach coupled with further femtosecond time-resolved measurements will gain more insight on this issue.

Finally, several derivatives of DPP and APP have been proposed as potential antitumor agents. ${ }^{62,63}$ It is thus of considerable interest to investigate whether the ESDPT reaction catalyzed by, e.g., the carboxylic group will induce the antitumor activity. Many amino acid side chains have abnormal $\mathrm{p} K_{\mathrm{a}}$ values in proteins. ${ }^{64}$ Therefore, unionized carboxylic acids might be involved in the hydrogen-bond interaction under biological conditions. Formation of cyclic dual hydrogen bonds allows an amino acid side chain incorporating carboxylic acid to discriminate between different nucleic acid bases, which serves an important role in the selective recognition of nucleic acid bases by proteins. ${ }^{65}$ Therefore, it is of great importance to probe the dual hydrogen bonding protein-nucleic acid interaction ${ }^{65}$ on the basis of the excited-state proton-transfer tautomerism of DPP and APP.

Acknowledgment. This work was supported by the National Science Council, Taiwan, R.O.C. (NSC89-2113-M-194-009).

\section{References and Notes}

(1) Taylor, C. A.; El-Bayoumi, M. A.; Kasha, M. Proc. Natl. Acad Sci. U.S.A. 1969, 63, 253.

(2) Ingham, K. C.; Abu-Elgheit, M.; El-Bayoumi, M. A. J. Am. Chem Soc. 1971, 93, 5023. 1674.

(3) Ingham, K. C.; El-Bayoumi, M. A. J. Am. Chem. Soc. 1974, 96,

(4) Watson, J. D.; Crick, F. H. C. Nature (London) 1953, 171, 964

(5) Watson, D. G.; Sweet, R. M.; Marsh, R. E. Acta Crystallogr. 1965, 19,573

(6) Hetherington, W. M., III; Micheels. R. H.; Eisenthal, K. B. Chem Phys. Lett. 1979, 66, 230

(7) Fuke, K.; Yoshiuchi, H.; Kaya, K. J. Phys. Chem. 1984, 88, 5840.

(8) Waluk, J.; Herbich, J.; Oelkrug, D.; Uhl, S. J. Phys. Chem. 1986 90, 3866.

(9) Fuke, K.; Kaya, K. J. Phys. Chem. 1989, 93, 614

(10) Tokumura, K.; Watanabe, Y.; Udagawa, M.; Itoh, M. J. Am. Chem. Soc. 1987, 109, 1346.

(11) Catalán, J.; Kasha, M. J. Phys. Chem. A 2000, 104, 10812

(12) Douhal, A.; Kim, S. K.; Zewail, A. H. Nature 1995, 378, 260.

(13) Folmer, D. E.; Poth, L.; Wisniewski, E. S.; Castleman, A. W., Jr. Chem. Phys. Lett. 1998, 287, 1

(14) Chachisvilis, M.; Fiebig, T.; Douhal, A.; Zewail, A. H. J. Phys. Chem. A 1998, 102, 669.

(15) Takeuchi, S.; Tahara, T. J. Phys. Chem. A 1998, 102, 7740.

(16) Fiebig, T.; Chachisvilis, M.; Manger, M.; Zewail, A. H.; Douhal, A.; Garcia-Ochoa, I.; de La Hoz Ayuso, A. J. Phys. Chem. A 1999, 103, 7419 .

(17) Chou, P. T.; Liao, J. H.; Wei, C. Y.; Yang, C. Y.; Yu, W. S.; Chou, Y. H. J. Am. Chem. Soc. 2000, 122, 986

(18) Douhal, A.; Guallar, V.; Moreno, M.; Lluch, J.-M. Chem. Phys. Lett. 1996, 256, 370

(19) Guallar, V.; Batista, V. S.; Miller, W. H. J. Chem. Phys. 1999, $110,9922$.

(20) Catalán, J.; Del Valle, J. C.; Kasha, M. Proc. Natl. Acad. Sci. U.S.A. 1999, 96, 8338 .

(21) McMorrow, D.; Aartsma, T. J. Chem. Phys. Lett. 1986, 125, 581.

(22) Moog, R. S.; Bovino, S. C.; Simon, J. D. J. Phys. Chem. 1988, 92 6545.

(23) Konijnenberg, J.; Huizer, A. H.; Varma, C. A. G. O.J. Chem. Soc., Faraday Trans. 2 1988, 84 (8), 1163.

(24) (a) Moog, R. S.; Maroncelli, M. J. Phys. Chem. 1991, 95, 10359

(b) Chapman, C. F.; Maroncelli, M. J. Phys. Chem. 1992, 96, 8430. 
(25) (a) Negrerie, M.; Bellefeuille, S. M.; Whitham, S.; Petrich, J. W.; Thornburg, R. W. J. Am. Chem. Soc. 1990, 112, 7419. (b) Negrerie, M.; Gai, F.; Bellefeuille, S. M.; Petrich, J. W. J. Phys. Chem. 1991, 95, 8663. (c) Negrerie, M.; Gai, F.; Lambry, J.-C.; Martin, J.-L.; Petrich, J. W. J. Phys. Chem. 1993, 97, 5046. (d) Chen, Y.; Rich, R. L.; Gai, F.; Petrich, J. W. J. Phys. Chem. 1993, 97, 1770. (e) Chen, Y.; Gai, F.; Petrich, J. W. J. Am. Chem. Soc. 1993, 115, 10158. (f) Rich, R. L.; Chen, Y.; Neven, D.; Negrerie, M.; Gai, F.; Petrich, J. W. J. Phys. Chem. 1993, 97, 1781. (g) Gai, F.; Rich, R. L.; Petrich, J. W. J. Am. Chem. Soc. 1994, 116, 735. (h) Smirnov, A. V.; English, D. S.; Rich, R. L.; Lane, J. Teyton, L.; Schwabacher, A. W.; Luo, S.; Thornburg, R. W.; Petrich, J. W. J. Phys. Chem. B 1997, 101, 2758 and references therein.

(26) (a) Chou, P. T.; Martinez, M. L.; Cooper, W. C.; McMorrow, D.; Collin, S. T.; Kasha; M. J. Phys. Chem. 1992, 96, 5203. (b) Chang, C. P.; Hwang W. C.; Kuo M. S.; Chou, P. T.; Clement, J. H. J. Phys. Chem. 1994, 98, 8801. (c) Chou, P. T.; Wei, C. Y.; Chang, C. P.; Chiu, C. H. J. Am. Chem. Soc. 1995, 117, 7259. (d) Chou, P. T.; Wei, C. Y.; Chang, C. P.; Kuo, M. S. J. Phys. Chem. 1995, 99, 11994.

(27) (a) Gordon, M. S. J. Phys. Chem. 1996, 100, 3974. (b) Chaban, G. M.; Gordan, M. S. J. Phys. Chem. A 1999, 103, 185.

(28) (a) Fernández-Ramos, A.; Smedarchina, Z.; Siebrand, W.; Zgierski, M. Z.; Rios, M. A. J. Am. Chem. Soc. 1999, 121, 6280. (b) Smedarchina, Z.; Siebrand, W.; Fernández-Ramos, A.; Gorb, L.; Leszczynski, J. J. Chem. Phys. 2000, 112, 566.

(29) Mente, S.; Maroncelli, M. J. Phys. Chem. A 1998, 102, 3860.

(30) Kyrychenko, A.; Stepanenko, Y.; Waluk, J. J. Phys. Chem. A 2000 $104,9542$.

(31) (a) Chou, P. T.; Wei, C. Y.; Wu, G. R.; Chen, W. S. J. Am. Chem. Soc. 1999, 121, 12186. (b) Chou, P. T.; Wu, G. R.; Wei, C. Y.; Cheng, C. C.; Chang, C. P.; Hung, F. T. J. Phys. Chem. B 1999, 103, 10042.

(32) Chou, P. T.; Wu, G. R.; Wei, C. Y.; Cheng, C. C.; Chang, C. P.; Hung, F. T. J. Phys. Chem. B 2000, 104, 7818.

(33) Chou, P. T.; Chen, Y. C.; Wei, C. Y.; Chen, W. S. J. Am. Chem. Soc. 2000, 122, 9322 .

(34) Chou, P. T.; Yu, W. S.; Wei, C. Y.; Chen, Y. M.; Yang, C. Y. J. Am. Chem. Soc. 2001, 123, 3599.

(35) Chou, P. T.; Liu, Y. I.; Liu, H. W.; Yu, W. S. J. Am. Chem. Soc.

2001, 123, 12119

(36) Schneller, S. W.; Luo, J. K. J. Org. Chem. 1980, 45, 4045.

(37) Clark, B. A. J.; Parrick, J. J. Chem. Soc., Perkin Trans. 1, 1974, 2270 .

(38) Girgis, N. S.; Larson, S. B.; Robins, R. K.; Cottam, H. B. J. Heterocycl. Chem. 1989, 26, 317.
(39) Schneller, S. W.; Luo, J. K. J. Org. Chem. 1980, 45, 4045

(40) Robison, M. M.; Robison, B. L. J. Am. Chem. Soc. 1955, 77, 457.

(41) Robison, M. M.; Robison, B. L. J. Am. Chem. Soc. 1956, 78, 1247.

(42) Demas, J. N.; Crosby, G. A. J. Phys. Chem. 1971, 75, 991.

(43) Chou, P. T.; Wei, C. Y.; Hung, F. T. J. Phys. Chem. B 1997, 101, 9119.

(44) Pimentel, G. C.; McClellan, A. L., Eds. The Hydrogen Bond, W. H. Freeman and Co.: 1960, p 368.

(45) Collins, S. T. J. Phys. Chem. 1983, 87, 3202.

(46) Staley, R. H.; Taagepera, M.; Henderson, W. G.; Koppel, I.; Beauchamp, J. L.; Taft, R. W. J. Am. Chem. Soc. 1977, 99, 326.

(47) Lippert, E. Z. Naturforsch. 1955, 10a, 541.

(48) Mataga, N.; Kubota, T. Molecular Interactions and Electronic Spectra; Marcel Dekker: New York, 1970; p 385.

(49) Bilot, L.; Kawski, A. Z. Naturforsch. 1962, 17a, 621

(50) Liptay, W. Z. Naturforsch. 1965, 20a, 1441.

(51) Lakowicz, J. R. Principles of Fluorescence Spectroscopy; Plenum Press: New York, 1983.

(52) Rotkiewicz, K.; Grellmann, K. H.; Grabowski, Z. R. Chem. Phys. Lett. 1973, 19, 315.

(53) Rettig, W.; Bonacic-Kouteckr, V. Chem. Phys. Lett. 1979, 62, 115.

(54) Rettig, W. Angew. Chem., Int. Ed. Engl. 1986, 25, 971 and references therein.

(55) Bhattacharyya, K.; Chowdhury, M. Chem. Rev. 1993, 93, 507 and references therein.

(56) Andréasson, J.; Holmén, A.; Albinsson, B. J. Phys. Chem. B 1999, $103,9782$.

(57) (a) Cramer, C. J.; Truhlar, D. G.J. Am. Chem. Soc. 1993, 115, 8810.

(b) Cramer, C. J.; Truhlar, D. G. J. Comput. Chem. 1992, 13, 1089.

(58) Lai, T.; Lim, E. C. Chem. Phys. Lett. 1979, 62, 507.

(59) Lim, E. C. J. Phys. Chem. 1986, 90, 6770.

(60) Madej, S. L.; Okajima, S.; Lim, E. C. J. Chem. Phys. 1976, 65, 1219.

(61) Parusel, A. B. J.; Rettig, W.; Rotkiewicz, K. J. Phys. Chem. A 2002, 106, 2293.

(62) Suhadolnik, R. J. Nucleosides as Biological Probe; Wiley-Interscience: New York, 1979; pp 298-353.

(63) Antonini, I.; Claudi, F.; Cristalli, G.; Franchetti, P.; Grifantini, M.; Martelli, S. J. Med. Chem. 1982, 25, 1258.

(64) Blow, D. M.; Steiz, T. A. Annu. Rev. Biochem. 1970, 39, 63. (b) Lancelot, G. J. Am. Chem. Soc. 1977, 99, 7037.

(65) Stormo, G. D.; Fields, D. S. Trends Biochem. Sci. 1998, 23, 109. 